\title{
La experiencia
}

\section{José Antonio Ocampo \\ Secretario General Adjunto \\ para Asuntos Económicos \\ y Sociales \\ de las Naciones Unidas \\ ex Secretario Ejecutivo \\ de la CEPAL \\ jaocampo@un.org}

\section{Camilo E. Tovar}

Departamento de Economía,

Universidad de

Wisconsin-Madison

cetovar@wisc.edu

\section{colombiana con \\ los encajes a los \\ flujos de capital}

Suavizar los ciclos de la cuenta de capitales y reducir la vulnerabilidad que estos traen consigo son objetivos deseables en los países en desarrollo. Este artículo evalúa las ventajas de aplicar un incentivo sencillo, no discrecional, preventivo (prudencial) y basado en un instrumento de precios que castiga drásticamente los pasivos de corto plazo en moneda extranjera. En especial, examina la efectividad de los controles a los flujos de capital que aplicó Colombia durante la década de los noventa. El análisis concluye que estas regulaciones fueron efectivas en reducir el volumen total de las entradas netas de capital y en mejorar la estructura de plazos de la deuda externa. El análisis econométrico sugiere que los flujos de capital guardaron relación directa con los diferenciales de tasas de interés, una vez que se controla por el costo adicional de los encajes no remunerados al endeudamiento externo. En consecuencia, el sistema colombiano de regulación del endeudamiento externo fue, a la vez, una política macroeconómica eficaz, que permitió que el país ejerciera un cierto control monetario y cambiario, y una "política de pasivos" que contribuyó a mejorar la estructura de vencimiento de la deuda externa. 


\section{I}

\section{Introducción}

En la actualidad, se reconoce ampliamente que los países en desarrollo - y en especial las economías emergentes - son extremadamente vulnerables a las fluctuaciones de los flujos internacionales de capital. El elevado costo económico y social que acarrea una reversión repentina de los flujos, en especial cuando conducen a crisis financieras, puede eliminar fácilmente las posibles ventajas que ofrece la mayor movilidad de capitales. En consecuencia, un objetivo fundamental de la política macroeconómica es reducir la intensidad de los ciclos de la cuenta de capitales, a fin de materializar los beneficios derivados de la integración financiera internacional, y al mismo tiempo disminuir la inestabilidad macroeconómica y la vulnerabilidad financiera asociadas a estos ciclos. ${ }^{1}$

En el decenio de los noventa, la mayoría de las economías emergentes tuvieron que enfrentar grandes entradas de capitales. ${ }^{2}$ La respuesta de política a estas entradas, aunque diversas, ${ }^{3}$ tuvo como objetivo mitigar los efectos de esos flujos para que no se tradujeran en una mayor apreciación cambiaria ni en una dependencia excesiva de corrientes de capital de corto plazo. ${ }^{4}$ Para evitar crisis financieras en un futuro va a ser necesario dilucidar qué políticas aplicadas en este período resultaron eficaces para manejar esta afluencia de capitales y, en especial, para impedir la acumulación excesiva de riesgo, que en algunos casos condujo a crisis financieras, o al colapso financiero cuando se interrumpió súbitamente el financiamiento externo.

Agradecemos los valiosos comentarios y sugerencias formulados por Sylvia Díaz, Charles Engel, Yuichi Kitamura, Jorge Tovar y Kenneth West a una versión anterior de este trabajo.

${ }^{1}$ Gourinchas, Valdés y Landerretche (2001) proporcionan un recuento detallado de las distintas fuentes de vulnerabilidad.

${ }^{2}$ Véase en Calvo, Leiderman y Reinhart (1996) un examen de los factores que determinaron este aumento de los flujos de capital hacia los países en desarrollo.

${ }^{3}$ Las principales políticas que se aplicaron para hacer frente al auge de los flujos de capital consistieron en medidas de austeridad fiscal, liberalización comercial acelerada, flexibilización de la política cambiaria, intervención esterilizada, liberalización de la salida de capitales y control a las entradas de capitales. Véase un buen análisis de estas políticas en Reinhart y Dunaway (1996).

${ }^{4}$ La apreciación acumulativa del tipo de cambio y, en especial, la excesiva dependencia de obligaciones de corto plazo en moneda extranjera parecen haber sido los principales determinantes de las últimas crisis financieras. Véanse Furman y Stiglitz (1998) y Rodrik y Velasco (2000).
La literatura reciente ha hecho énfasis en la necesidad de adoptar estrategias para prevención de crisis que incluyan políticas macroeconómicas contracíclicas durante los periodos de afluencia de capitales (esto es, políticas contractivas en esa fase del ciclo) y sólidos esquemas de regulación prudencial y de supervisión para los sistemas financieros nacionales. Si bien se reconoce que este tipo de instrumentos son imprescindibles y deseables, las políticas macroeconómicas contracíclicas pueden verse comprometidas durante los periodos de auge por los flujos de capital adicionales que ellas mismas generan (por ejemplo, los mayores flujos generados por la esterilización monetaria, a través de sus efectos sobre las tasas de interés). Es más, se reconoce que los efectos de la regulación prudencial pueden eludirse mediante el endeudamiento directo en el exterior. Por lo tanto, tal vez convenga complementar estas políticas preventivas con instrumentos de política dirigidos directamente al origen de las presiones macroeconómicas y financieras que confrontan los países en desarrollo en períodos de bonanza, esto es, a la excesiva entrada de capitales. ${ }^{5}$

$\mathrm{Al}$ respecto, una política que ha sido considerada potencialmente efectiva es la de controlar la entrada de capitales mediante un sistema basado en un instrumento de precios, estableciendo un encaje o depósito no remunerado sobre el endeudamiento externo. ${ }^{6}$ En especial, se ha planteado que esta clase de regulación de la cuenta de capital puede ser útil como mecanismo de política macroeconómica y también como "política de pasivos" para mejorar el perfil de la deuda de los países en desarrollo.

Visto como un instrumento de política macroeconómica, esta clase de regulaciones está dirigida directamente a la fuente que genera los ciclos de auge y crisis: la inestabilidad de los flujos de capital. Si logran reducir las entradas totales de capital, otorgarán un alivio durante los períodos de euforia financiera mediante la aplicación de políticas monetarias contractivas y/o la disminución de las presiones que apuntan a la aprecia-

\footnotetext{
5 Véanse Furman y Stiglitz (1998), Williamson y Mahar (1998), Eichengreen (1999) y Ocampo (2003a y 2003b).

${ }^{6}$ A lo largo del trabajo se utilizará principalmente la expresión "encaje", también se usará como sinónimo el término "depósito" (en el banco central).
} 
ción cambiaria. Si resulta eficaz, también reducirán o eliminarán el costo cuasi-fiscal asociado a la esterilización de la acumulación de reservas.

Vistas como política de pasivos, estas regulaciones tienen en cuenta que el mercado premia el endeudamiento externo de largo plazo (Rodrik y Velasco, 2000). Esto indica que, en períodos de incertidumbre, el mercado responde a las necesidades brutas (más que a las netas) de financiamiento, lo que significa que el endeudamiento de corto plazo no es neutral desde el punto de vista financiero. Bajo estas circunstancias, una estructura de vencimientos en la que predominan obligaciones de más largo plazo reduce los riesgos de iliquidez. De ahí que en los períodos de auge las medidas para mejorar las estructuras de vencimientos de las obligaciones internas y externas del sector público y del sector privado debieran ser un componente esencial de la gestión de la política económica.

En general, la literatura empírica disponible confirma la efectividad de los encajes a los ingresos de como "política de pasivos", es decir, el hecho de que desalientan la entrada de capitales de corto plazo y, en consecuencia, mejoran la estructura de vencimiento de las obligaciones externas. Sin embargo, aún es motivo de controversia si estos controles reducen o no la afluencia neta de capital y si alivian las presiones so- bre el tipo de cambio. De hecho, son pocos los estudios empíricos que han analizado estos temas, y la evidencia existente se basa sobre todo en la experiencia de Chile. ${ }^{7}$

El presente ensayo analiza la efectividad de las regulaciones o controles a las entradas de capital basado en un instrumento de precios (el encaje) a partir de la experiencia de Colombia en la década de los noventa. En especial, examina si estos controles alteraron el volumen y composición de las entradas de flujos financieros. Tras esta introducción, el resto del trabajo se organiza de la siguiente manera: la sección II ofrece una visión general del marco regulatorio para las transacciones en divisas que aplicó Colombia en la década de los noventa; la sección III examina el marco conceptual del análisis; la sección IV presenta evidencia econométrica del impacto de los controles a las entradas de capitales sobre el volumen y la estructura de vencimientos de los flujos netos de capital privado que involucran transacciones en efectivo, complementándola con un análisis de la sensibilidad de los flujos de capital a los diferenciales de tasas de interés antes y después de que Colombia liberalizara la cuenta de capitales. Para este fin se realizan algunos ejercicios econométricos adicionales. Finalmente, la sección V ofrece algunas conclusiones.

\section{II}

\section{La regulación de la cuenta de capitales en Colombia}

A comienzos de la década de los noventa, Colombia liberalizó las transacciones cambiarias como parte de un programa más amplio de reformas estructurales. El proceso se inició en 1991, cuando se modificó el sistema de control cambiario que se había aplicado durante un cuarto de siglo, a fin de permitir que los intermediarios financieros realizaran transacciones en moneda extranjera sin estar sujetos a controles previos del banco central (Banco de la República) y que las empresas utilizaran sus cuentas bancarias para administrar los ingresos y gastos en divisas. Pese a esta liberalización, las transacciones siguieron estando muy reglamentadas y, en especial, sujetas a la obligación de canalizarlas a través de intermediarios financieros legalmente autorizados para operar en el mercado. Adicionalmente, la reforma de 1991 fijó un plazo mínimo de un año a los créditos externos, ${ }^{8}$ y mantuvo normas severas respecto al uso final de los recursos provenientes de esta clase de créditos, los que debían destinarse a financiar operaciones comerciales o de inversión. En febrero de 1992 se permitió, por primera vez, que las empresas contrataran créditos de corto plazo para capital de trabajo.

\footnotetext{
${ }^{7}$ Entre los estudios sobre los efectos de los encajes a los ingresos de capital en Chile, cabe mencionar los de De Gregorio, Edwards y Valdés (2000), Edwards (1999 y 1998), Agosin y Ffrench-Davis (1999 y 1996), Budnevich y Le Fort (1997) y Valdés y Soto (1998). Para un panorama general, véase Montiel y Reinhart (1999).

${ }^{8}$ Se contemplaron algunas excepciones para determinado tipo de créditos comerciales.
} 


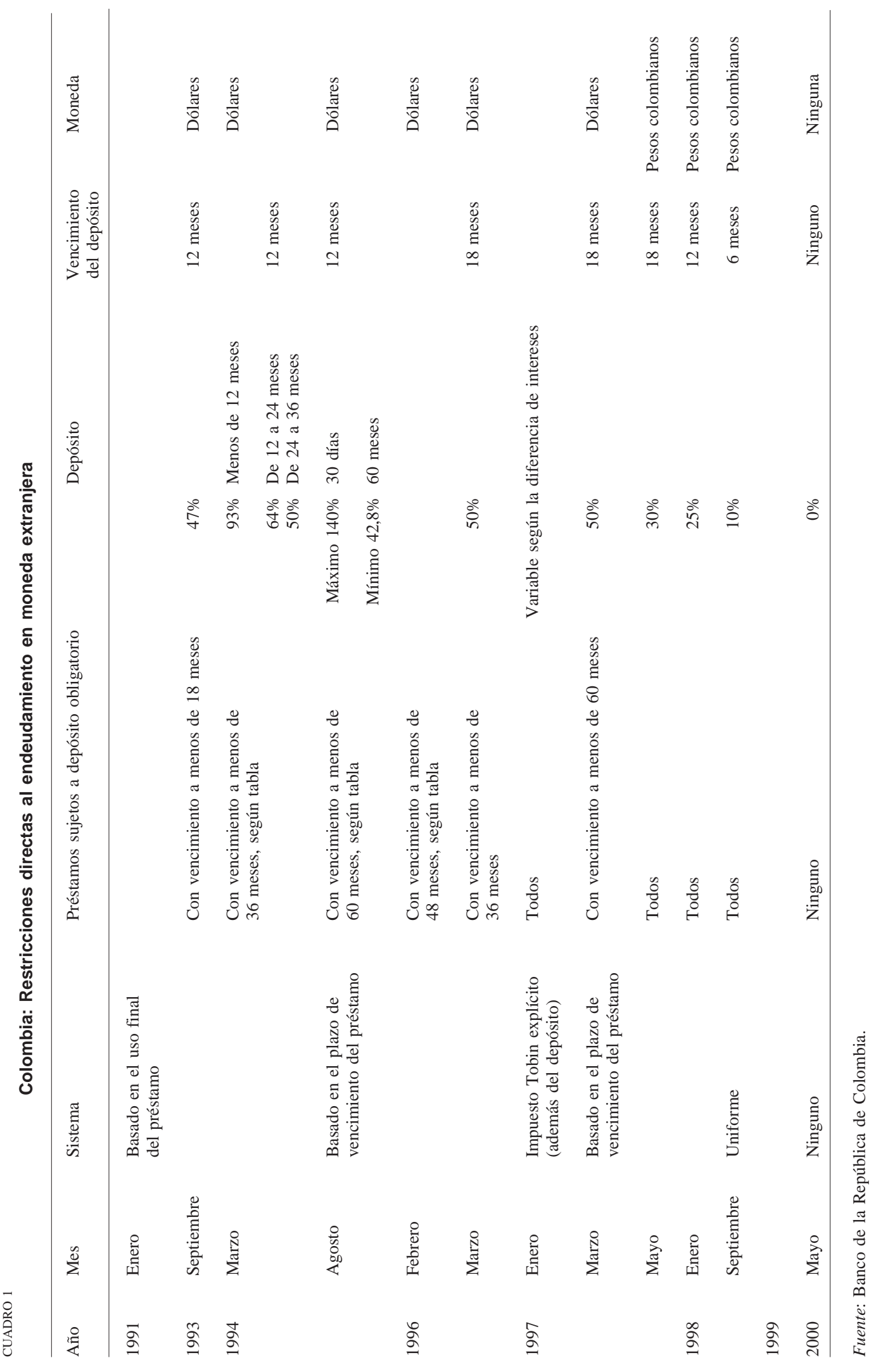


Recién en septiembre de 1993 se introdujeron cambios más importantes. Durante esta segunda etapa de reformas, el sistema de regulación de los flujos de capital basado en su uso final fue sustituido por otro basado en el plazo de vencimiento de las obligaciones en moneda extranjera. Además, se autorizó a los intermediarios financieros locales para otorgar préstamos en moneda extranjera a empresas locales y a residentes, sin importar el uso final del crédito; conceder préstamos en divisas a extranjeros, e invertir en activos líquidos en el exterior. Sin embargo, todas las deudas en moneda extranjera debían ser registradas en el banco central, incluidos los créditos comerciales de corto plazo, que antes no estaban sujetos a este requisito.

Concretamente, el nuevo sistema exigió a todos los créditos a plazos inferiores de cierto vencimiento, que aquí denominaremos "plazo mínimo de vencimiento", a mantener un encaje o depósito no remunerado en dólares en el banco central, a una tasa y durante un período preestablecidos. Este encaje se asemejaba a un impuesto, ya que podía redimirse de inmediato a tasas de descuento preestablecidas. ${ }^{9}$ Durante los años siguientes, el sistema fue objeto de modificaciones importantes (cuadro 1). En septiembre de 1993 se estableció un encaje obligatorio en dólares por un año, equivalente al $47 \%$ de todos los préstamos con plazos inferiores a un plazo mínimo de vencimiento de 18 meses. ${ }^{10}$ En marzo de 1994, el plazo mínimo de vencimiento mínimo se fijó en tres años y se establecieron tres tipos de encajes obligatorios en dólares: 93\% para los préstamos con vencimiento de hasta un año, $64 \%$ para los que vencían hasta dos años y 50\% para los préstamos de hasta tres años de plazo. En agosto de 1994, el plazo mínimo de vencimiento se aumentó a cinco años y el vencimiento del depósito se equiparó con el del crédito. El encaje se estableció de acuerdo a una tabla compleja, con un máximo de $140 \%$ para los préstamos a menos de 30 días y un mínimo de $42 \%$ para aquellos con vencimiento a cinco años. En febrero de 1996 se rebajó el plazo mínimo de vencimiento a cuatro años y se estableció una nueva tabla de encajes, y en marzo del mismo año se redujo nuevamente el plazo mínimo a tres años y se fijó una tasa de depósito uniforme, con vencimiento a 18 meses, equivalente a $50 \%$ del préstamo.

En enero de 1997, además del encaje obligatorio, el gobierno estableció un impuesto (Tobin) explícito sobre todos los flujos de capital. El impuesto fue de corta vida, ya que fue declarado inconstitucional en marzo. Como reacción inmediata al fallo de la Corte Constitucional, las autoridades económicas aumentaron de forma drástica los encajes sobre los créditos externos. El plazo mínimo de vencimiento se aumentó a cinco años y se mantuvo la tabla de encajes. En mayo de 1997, se introdujo un sistema más sencillo, similar al aplicado en Chile, de acuerdo con el cual se estableció un encaje uniforme en moneda nacional, con vencimiento a 18 meses, para todos los préstamos. En consecuencia, se abandonó el principio del plazo mínimo de vencimiento y los encajes en dólares fueron sustituidos por depósitos en pesos. Para responder a las presiones creadas por la crisis financiera internacional, en enero y septiembre de 1998 se redujo el monto y el período de tenencia de los depósitos. Finalmente, en mayo del año 2000 se eliminó el encaje, aunque se mantuvo la posibilidad de restablecerlo.

\section{III}

\section{Marco conceptual}

Para analizar los efectos de la regulación aplicable a los flujos de capital privado, se utilizará un modelo simple de inversiones de cartera basado en la condición de paridad de intereses. ${ }^{11-12}$ Así, si se supone una

\footnotetext{
${ }^{9}$ Pese a tratarse de un encaje no remunerado, ello no significaba que no pudiera tener rentabilidad positiva o negativa. De hecho, esa rentabilidad podía producirse debido a variaciones del valor relativo de la moneda en que se realizaba el depósito.

${ }^{10}$ Así, por cada 100 dólares obtenidos en préstamo en el extranjero había que mantener en el banco central (Banco de la República) un depósito de 47 dólares durante un año.
}

sustitución de los activos nacionales y extranjeros, un inversionista neutro frente al riesgo elegirá mantener

\footnotetext{
11 Véase un análisis sobre cómo medir la movilidad del capital en Frankel (1992) y Schulze (2000)

${ }^{12}$ Cabe señalar que una alternativa podría ser la de utilizar un modelo que tenga en cuenta el precio de los activos. Sin embargo, el problema de emplear estos modelos para verificar la existencia de barreras a las inversiones internacionales es que ellos suelen no tener capacidad explicativa adecuada. Las pruebas que utilizan la integración de los mercados como hipótesis nula no pueden rechazar la existencia de barreras importantes por medios econométricos debido a que las estimaciones son demasiado imprecisas (véase Schulze, 2000, p. 162).
} 
activos externos o nacionales según el diferencial de tasas de interés no cubierto o factor de arbitraje, es decir, la diferencia entre las tasas de interés internas y externas y la devaluación esperada. Esto puede expresarse de la siguiente manera:

$$
A=\frac{1+i}{\left(1+i^{*}\right)\left(1+d^{e}\right)}-1
$$

donde $i$ es la tasa de interés interna (pasiva o de depósito), $i^{*}$ es la tasa de interés externa equivalente y $d^{e}$ es la devaluación esperada. Si $A>0$, los inversionistas optarán por tener activos nacionales y, por lo tanto, habrá entrada de capitales. Por otra parte, si $A<0$, los inversionistas optarán por tener activos extranjeros y, en consecuencia, habrá salida de capitales del país. Finalmente, si $A=0$, los inversionistas serán indiferentes para tener activos externos o nacionales, en cuyo caso su cartera se encontrará en equilibrio y no habrá flujos de capital asociados a factores de arbitraje.

Sin embargo, si los flujos de capital están sujetos a un encaje obligatorio, habrá que ajustar el factor de arbitraje para tener en cuenta el costo de oportunidad de esa exigencia. ${ }^{13}$ Como consecuencia, el diferencial de intereses puede calcularse como sigue:

$$
A=\frac{1+i}{1+\phi}-1
$$

donde $\phi$ es el costo anual total del endeudamiento externo. La expresión exacta de este costo $\phi$ puede derivarse del hecho de que el valor presente de los encajes por dólar obtenido en préstamo, $C$, es:

$$
C=r\left(1-\frac{1+d^{e} \theta}{1+i}\right)^{t d}
$$

en el que $r$ es el coeficiente del encaje por dólar obtenido en préstamo en el extranjero y $t d$ el plazo de vencimiento del encaje (o depósito). Además, en el período en que la reserva obligatoria se expresaba en dólares (septiembre a mayo de 1997), $\theta$ es igual a 1 , mientras

\footnotetext{
${ }^{13}$ El marco utilizado en este trabajo parte del supuesto de que la sustitución de los activos internos y externos es imperfecta. Teóricamente habría que incluir en el análisis una prima por concepto de riesgo-país; sin embargo, no hay una medida consistente de esta clase de primas en Colombia en el período examinado. Así, pues, implícitamente se supone que las primas de riesgo dependen de los factores incluidos en el estudio, esto es, la regulación del capital y las variables ficticias que captan el entorno financiero externo.
}

que en el período en que se denominaba en pesos (mayo de 1997 a mayo de 2000) $\theta$ es igual a 0.

Dada la ecuación [3] el valor futuro del encaje puede calcularse de la siguiente manera: ${ }^{14}$

$$
L f=\left[\left(1+i^{*}\right)\left(1+d^{e} \theta\right)\right]^{t c}+C(1+i)^{t c}
$$

donde $t c$ es el vencimiento del crédito. Por lo tanto, la ecuación [4] nos permite calcular el costo anual total del crédito $\phi$ :

$$
\phi=L f^{(1 / t c)}-1
$$

que se utiliza en la ecuación [2] para calcular el factor de arbitraje. Por último, el equivalente tributario del encaje aplicable a los créditos externos puede calcularse mediante la siguiente expresión:

$$
\tau=\frac{1+\phi}{\left(1+i^{*}\right)\left(1+d^{e}\right)}-1
$$

El equivalente tributario es función de tres variables principales: i) la tasa del encaje, $r$; ii) la relación entre el plazo de vencimiento del préstamo y el del encaje, y iii) el hecho de que, durante el período en que los encajes se constituían en dólares (entre septiembre de 1993 y mayo de 1997), su costo de oportunidad guardaba relación directa con las tasas de interés e inversa con el ritmo de devaluación. Este útimo efecto era contrario al efecto directo de la tasa de devaluación sobre el costo del endeudamiento externo, característica que hacía que el encaje tuviera un efecto estabilizador (parcial) sobre el costo del endeudamiento externo. De forma más precisa, si el costo de los créditos bajaba, porque el ritmo de la devaluación era lento o había una apreciación del tipo de cambio, se elevaba el equivalente tributario del encaje, mientras que lo contrario ocurría si aumentaba el costo del crédito como consecuencia de una devaluación más acelerada. Sin embargo, este efecto estabilizador desapareció en mayo de 1997 después de reemplazar el sistema de encajes en dólares por uno en el cual dicha obligación se constituía en pesos.

El gráfico 1 muestra el cálculo del costo total de los créditos externos, el equivalente tributario del encaje aplicable a los créditos a $6,12,18,24$ y 36 me-

\footnotetext{
14 Como el encaje y el préstamo pueden tener distinto plazo de vencimiento, es más fácil calcular el valor futuro del primero.
} 
A. Efectos del encaje en el costo relativo de los créditos externos

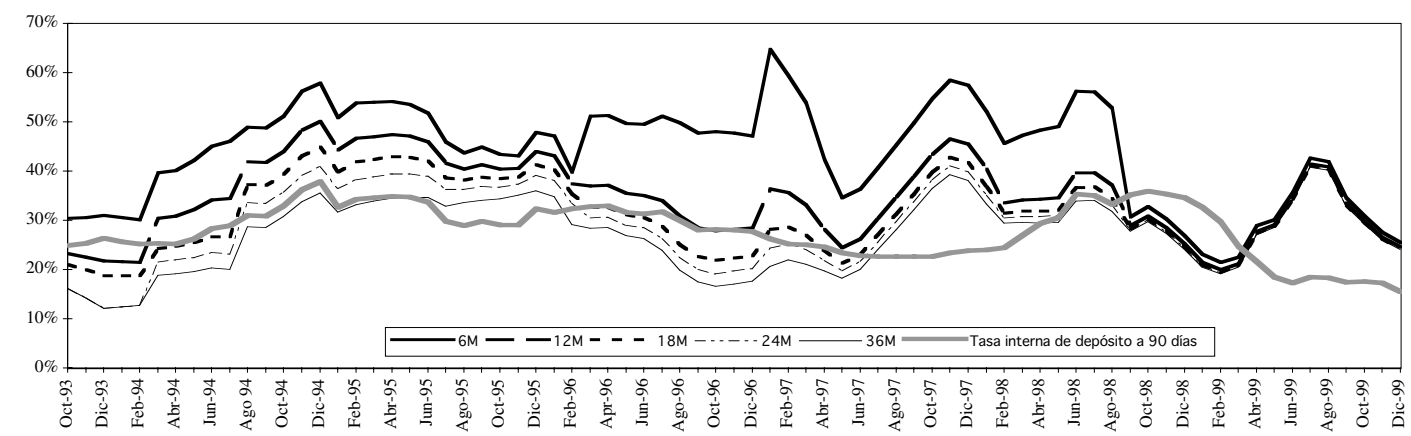

B. Equivalente tributario del encaje
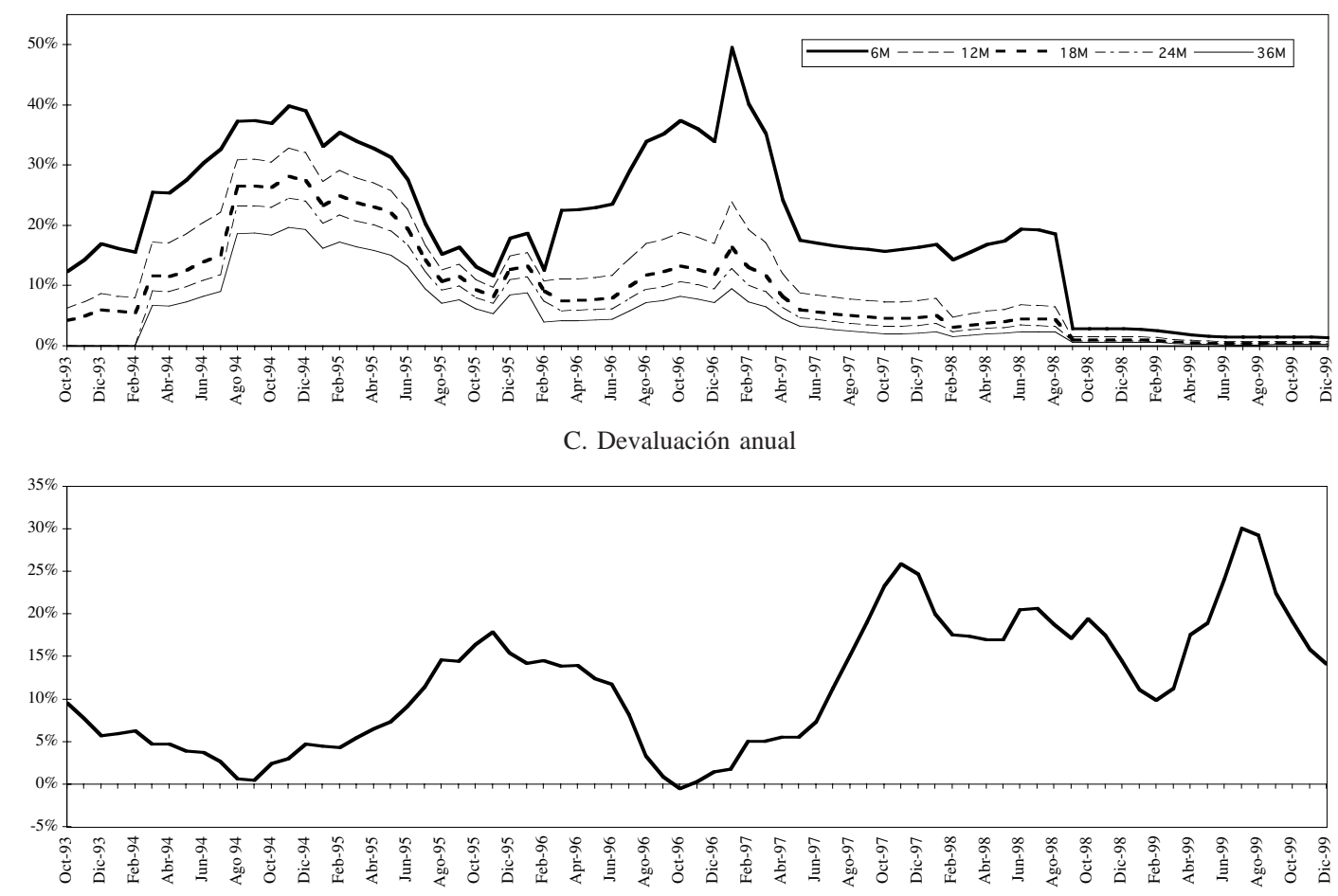

Fuente: Cálculos basados en datos del Banco de la República de Colombia.

ses, ${ }^{15}$ y la tasa anual de devaluación nominal. Estas cifras revelan que durante la mayor parte de la década de los noventa la regulación encareció mucho los cré-

\footnotetext{
${ }^{15}$ Para los efectos del cálculo, $i$ es la tasa de interés interna (pasiva o de depósito) a 90 días, $i *$ es la tasa de interés equivalente en los Estados Unidos, mientras que $d^{e}$ se calculó utilizando una combinación lineal de la devaluación nominal anualizada en los 12 meses anteriores y los 12 posteriores, asignando igual ponderación a cada observación.
}

ditos externos de corto plazo, en especial aquellos a seis meses. Cabe señalar, sin embargo, que hasta comienzos de 1997 el elevado costo del endeudamiento externo estuvo asociado a la evolución del equivalente tributario de los encajes. No obstante, luego de la modificación normativa de mayo de 1997, el alto costo de los créditos externos reflejó, sobre todo, las fuertes presiones hacia la devaluación del tipo de cambio nominal, vinculadas con las crisis financieras internacionales de la época. 


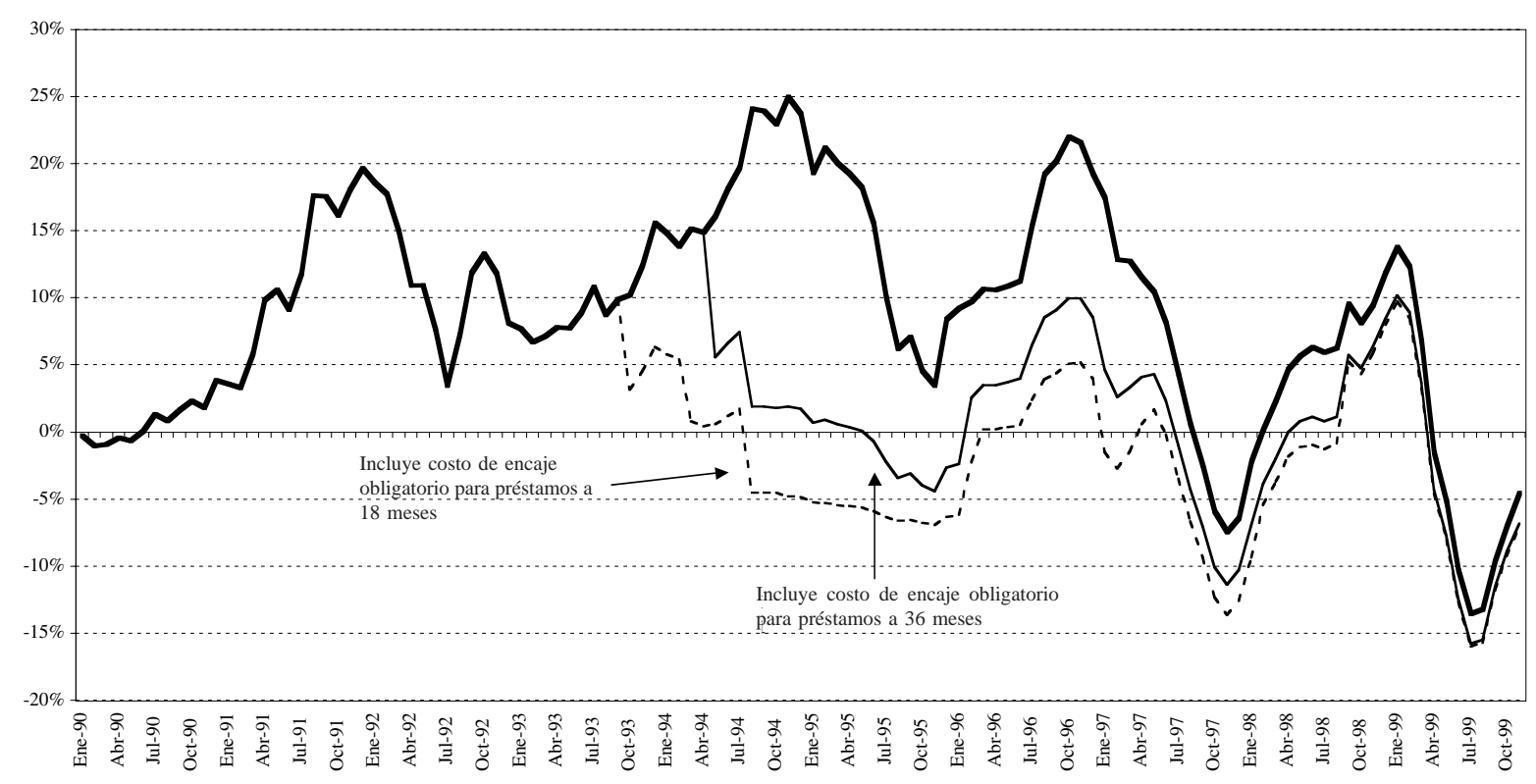

B. Flujos de capital privado en efectivo

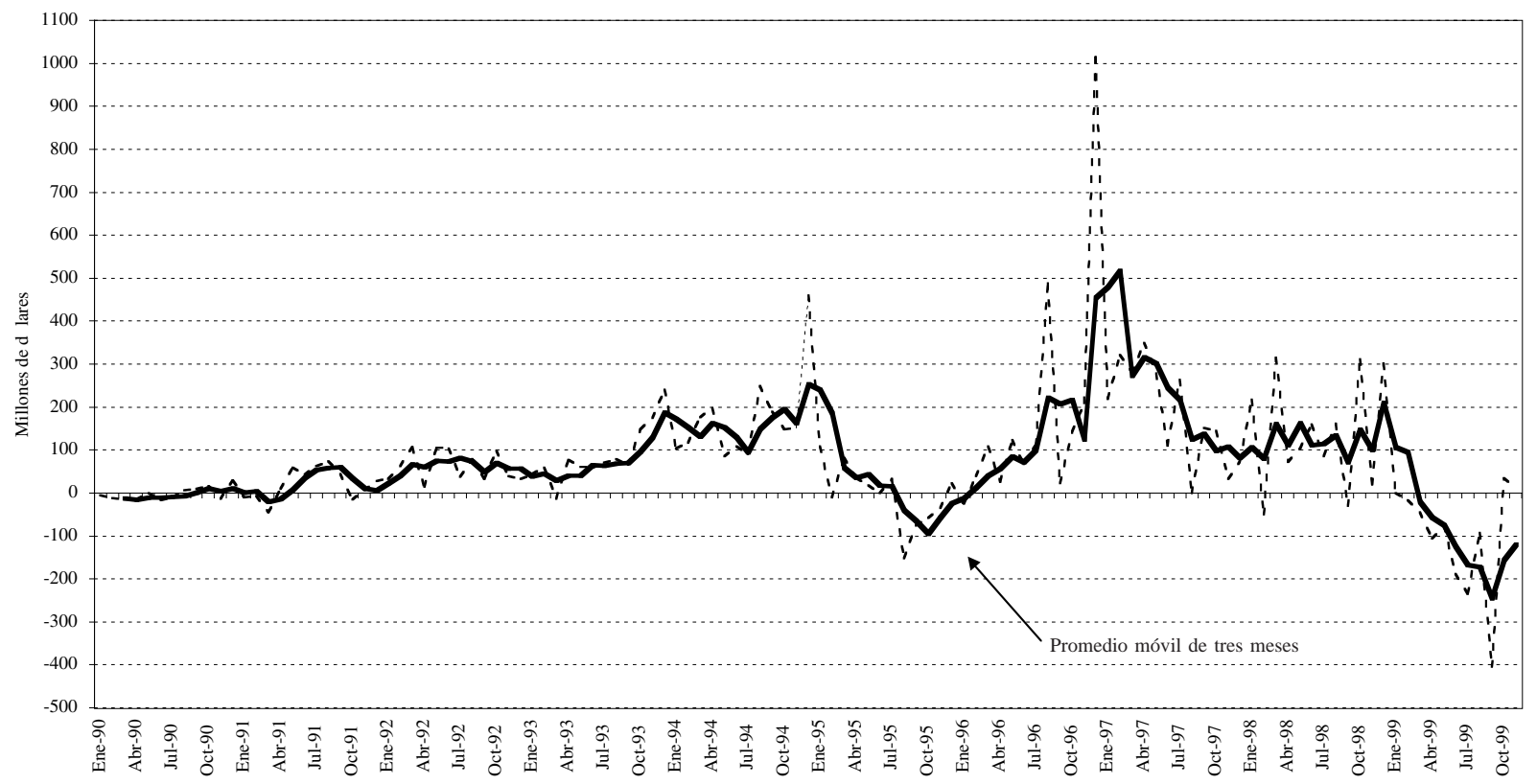

Fuente: Cálculos basados en datos del Banco de la República de Colombia. 
El gráfico 2 ofrece información básica acerca de los diferenciales de tasas de interés, incluido y excluido el costo de los encajes para préstamos a 18 y 36 meses, respectivamente, ${ }^{16}$ y sobre los flujos de capital privado que involucran transacciones en efectivo o, simplemente, flujos de capital en efectivo ${ }^{17}$ (en el gráfico se incluye un promedio móvil de tres meses a fin de mostrar la tendencia de los datos). La sección A del gráfico muestra la presencia de fuertes incentivos a la entrada de capitales entre el segundo trimestre de 1991 y mediados de 1992, entre el tercer trimestre de 1993 y el segundo de 1995, desde comienzos de 1996 hasta el segundo trimestre de 1997 y, finalmente, en el último trimestre de 1998 y el primero de 1999.

Cabe señalar que, en el caso de los préstamos a 36 meses, el incentivo para endeudarse se redujo efectivamente después de marzo de 1994 y se eliminó por completo después de que comenzaron a regir las normas adoptadas en agosto de 1994. De hecho, los diferenciales de tasas de interés, incluido el encaje, se tornaron negativos y hacia mediados de 1995 desapareció totalmente el incentivo para endeudarse en el exterior. La brusca interrupción de los flujos de capital que se produjo en el tercer trimestre de 1995 se explica por el efecto combinado de esta reglamentación restrictiva y de la devaluación más acelerada del tipo de cambio nominal (véase la sección B del gráfico 2). En la segunda mitad de 1996, las normas más flexibles que se habían introducido a comienzos del año, unidas a la apreciación del tipo de cambio nominal, provocaron un incremento de la afluencia de capitales. Hacia fines de 1996, hubo movimientos especulativos que amenazaron con romper el piso de la banda cambiaria (lo que se refleja en montos extraordinarios de entradas de capitales en diciembre de 1996). Como se discutió en la sección II, en enero de 1997 el gobierno reaccionó a esta masiva entrada de capitales mediante la aplicación de un impuesto (Tobin) explícito. Las medidas de política adoptadas en marzo y mayo de ese año ayudaron a neutralizar la afluencia de capital. Efectivamente, la entrada de capitales se mantuvo estable hasta comienzos de 1999, cuando la crisis brasileña desencadenó una salida acelerada de ellos y generó fuertes presiones hacia la devaluación.

\section{IV}

\section{Determinantes de los flujos de capital privado}

\section{Una revisión de la literatura}

Un breve examen de la literatura existente sobre la efectividad de los controles de los flujos de capital basados en un instrumento de precios (los encajes) que se aplicaron en Colombia proporciona un context útil para analizar la evidencia econométrica que se presenta más adelante. El primer intento de estudiar los determinantes de los flujos de capital tras las políticas de liberalización adoptadas en 1993 fue el de Cárdenas y Barrera (1997). Estos autores sostienen que la regulación de los flujos de capital fue efectiva en cambiar su composición, generando una estructura de vencimiento a más largo plazo, pero que, en cambio, fue inefectiva en términos de reducir el volumen de los flujos netos de capital. Sus argumentos están basados en tres resultados. Primero, utilizando datos mensuales

\footnotetext{
16 Véase la ecuación (2).

${ }^{17}$ Es decir, empleando la terminología colombiana, flujos que afectan la balanza cambiaria.
}

correspondientes al período comprendido entre enero y junio de 1996, encuentran que no hay relación entre los flujos de capital y los diferenciales de tasas de interés cuando se emplea el equivalente tributario de los encajes correspondientes a préstamos de corto plazo (18 a 24 meses). ${ }^{18}$ Segundo, utilizando variables dicotómicas, encuentran señales de comportamiento especulativo antes y después de que se modificaran las normas correspondientes. Por último, encuentran que las variables de control no tienen efectos permanentes, como lo indica la insignificancia estadística de los coeficientes de las variables dicotómicas que cubren el período en que se aplicaron normas determinadas. La única excepción es una variable ficticia correspondiente al período comprendido entre enero de 1995 y junio de 1996, que interpretan como un "efecto tequila".

\footnotetext{
${ }^{18}$ La fórmula utilizada por Cárdenas y Barrera (1997) para medir el equivalente tributario de los encajes es distinta de la examinada en la sección anterior y resulta imprecisa.
} 
Según Villar y Rincón (2003), Cárdenas y Barrera (1997) no encuentran evidencia alguna de que los flujos de capital estén relacionados con el equivalente tributario de los encajes, porque no tienen en cuenta los efectos de los controles administrativos que existían antes de 1993. Los efectos de estos controles y el cambio de sistema introducido en 1993 han sido analizados por Ocampo y Tovar (1997) empleando estadísticas mensuales correspondientes al período comprendido entre enero de 1990 y diciembre de 1996. Estos autores llegan a la conclusión de que el control a las entradas de capitales alteró no sólo la estructura de los vencimientos, sino también el volumen de los ingresos netos de capitales. A diferencia de Cárdenas y Barrera (1997), encontraron evidencia de arbitraje de intereses al incorporar el equivalente tributario de los encajes aplicables a los créditos de corto plazo (18 y 36 meses). Es más, pruebas para capturar los efectos transitorios de las distintas regulaciones mediante variables dicotómicas sugieren que hubo ajustes en los acervos de endeudamiento externo, una vez introducidas las medidas de liberalización de febrero de 1992 y septiembre de 1993. También encuentran evidencia de un comportamiento especulativo previo a la introducción de las normas de agosto de 1994 (véase una explicación de este hecho en la sección siguiente), aunque también que este cambio de política tuvo efectos apreciables, aunque tardíos, que redujeron los flujos de capital en montos superiores al incremento en el endeudamiento que se había producido como resultado de la especulación. Este resultado constituye una explicación alternativa a la interpretación de Cárdenas y Barrera sobre el "efecto tequila": el control sobre la entrada de capitales introducido en agosto de 1994 fue eficaz, pero con un rezago. Esta interpretación alternativa es razonable, dado que la evolución del margen (spread) de los bonos soberanos indica que, en Colombia, la crisis mexicana de entonces sólo tuvo consecuencias menores. Además, los flujos netos globales de capital a América Latina sugieren que, en el mejor de los casos, los efectos de contagio sólo fueron importantes durante el primer trimestre de $1995 .{ }^{19}$

En otro trabajo, Rincón (1999) construye una medida alternativa de los flujos mensuales de capital

\footnotetext{
19 Cárdenas y Barrera (1997) y Ocampo y Tovar (1997) también estudiaron si el arbitraje de los tipos de interés se filtró a través de las cuentas del comercio de bienes y de servicios. El primero de estos estudios encontró pruebas de filtración a través de la cuenta de servicios, no así a través de la de comercio de bienes; el segundo no encontró evidencia de ello en ninguno de los dos casos.
}

privado de corto plazo para evaluar la efectividad de los controles a los flujos. ${ }^{20}$ Sus resultados, basados en un análisis de cointegración, confirman la efectividad de los controles en términos de su capacidad para regular los flujos de capital. En particular, este autor comprueba la existencia de una relación estadísticamente significativa y negativa entre los flujos de capital y el equivalente tributario de los encajes, medidos de acuerdo a la metodología sugerida por Ocampo y Tovar (1997). Sin embargo, no verifica si hubo ajustes en el volumen total de los flujos asociados a los cambios en las regulaciones, lo que constituye un punto vital en el debate sobre la efectividad de los controles del capital (Cárdenas y Barrera, 1997; Ocampo y Tovar, 1997).

Cárdenas y Steiner (2000) examinan los determinantes de los flujos de capital privado, utilizando datos trimestrales para el período 1987-1997. En su estudio emplean medidas alternativas de los flujos de capital, que incluyen, además de la balanza cambiaria, estimativos de los flujos de capital que se filtran a través de transacciones de servicios no factoriales. ${ }^{21}$ Estas medidas se emplean en dos ejercicios de regresión de los determinantes de los flujos de capital. Primero, corren una regresión contra una variable representativa del entorno externo de la región (según se refleja en los recursos captados por los países latinoamericanos en los mercados internacionales), y luego, contra el diferencial efectivo de tasas de interés, incluyendo el costo de los encajes bajo diferentes plazos de vencimiento. ${ }^{22}$ Sus resultados indican que los flujos de capital fueron extremadamente sensibles al entorno externo, así como a los diferenciales de tasas de interés, incluido el costo de los encajes. Pese a que sugieren que estos resultados "debieran interpretarse como prueba indirecta de que en Colombia los impuestos Tobin no sólo afectaron los plazos de vencimiento de las

\footnotetext{
${ }^{20}$ Este estudio utilizó series mensuales construidas con datos trimestrales de la balanza de pagos, y no los flujos en efectivo de la balanza cambiaria del banco central, que se emplean en todos los demás trabajos. La principal diferencia entre los datos de uno y otro origen es que abordan el financiamiento del comercio de diversa manera (véase la nota 26 más adelante). Cabe señalar que uno de los inconvenientes de las cuentas de la balanza de pagos es que sólo se dispone de ellas por trimestres, mientras que los flujos mensuales de capital son muy volátiles (gráficos 1 y 2). Por lo tanto, utilizando datos trimestrales no es posible captar adecuadamente la dinámica de dicha variable.

${ }^{21}$ En este trabajo se utilizaron tres medidas de los flujos de capital privado. La más simple es el saldo de la cuenta de capital en divisas del banco central. Las otros dos añaden, respectivamente, el componente "transitorio" del saldo de los servicios no factoriales privados y el saldo total de los servicios no factoriales.

${ }^{22}$ Se utilizaron vencimientos a $18,24,36$ y 60 meses.
} 
corrientes de capital privado, sino que redujeron su monto absoluto", ${ }^{23}$ Cárdenas y Steiner (2000) se apresuran a señalar que este punto de vista no se ve confirmado por otros ejercicios.

En uno de los ejercicios alternativos, Cárdenas y Steiner realizan regresiones de mínimos cuadrados ordinarios de los movimientos de capital, controlando por los diferenciales de tasas de interés, pero excluyendo el costo de los encajes y la variable del entorno externo. En este ejercicio se captan los efectos de los controles de capital, utilizando una variable ficticia para el período posterior a marzo de 1993 en que rigió esa normativa. Los resultados obtenidos indican que los flujos de capital tienen una relación directa y significativa con los diferenciales de tasas de interés y que, a la vez, dependen poco de factores externos, se incluya o no dicha variable ficticia. Esta última sólo tiene efectos significativos en un caso, y en algunos ejercicios exhibe signo positivo, por lo cual los autores concluyen que, si bien los impuestos Tobin efectivamente inducen un descenso del endeudamiento externo de corto plazo, fomentan un mayor endeudamiento externo en general; y que esto último probablemente se debe a que mientras por definición los impuestos Tobin reducen el diferencial de tasas de interés, tal vez hagan relativamente más atractivo al país en su conjunto. Esta explicación sugiere, sin embargo, que los autores podrían estar interpretando erradamente lo captado por la variable ficticia. En realidad, si lo que domina el resultado se debe a cuán atractivo es el país, la variable ficticia seguramente está captando otra cosa, como son los "factores de atracción" ("pull factors") asociados a las reformas estructurales. ${ }^{24}$

Finalmente, Villar y Rincón (2003) examinan la efectividad de los controles de los flujos de capital desde una perspectiva diferente. Su principal interés es determinar si los encajes a los ingresos de capital ayudan a las autoridades a manejar mejor las disyuntivas que enfrenta una economía abierta, en especial a evitar una fuerte apreciación de la moneda nacional y al mismo tiempo conservar el control de las tasas de in-

\footnotetext{
${ }^{23}$ El texto entre comillas es una cita original traducida del inglés. ${ }^{24}$ Las explicaciones de los flujos de capital hacia los países en desarrollo se han enfocado fundamentalmente en dos tipos de factores: los factores de expulsión (push) y los de atracción (pull). Los primeros operan haciendo menos atractivos los flujos de capital hacia los países industrializados. Los segundos atraen capital hacia los países en desarrollo como resultado del mejoramiento de las características de riesgo/rentabilidad de los activos emitidos por este tipo de países. Finalmente, un tercer tipo de factor puede estar relacionado con variaciones del grado de integración financiera, debido a modificaciones normativas (véase Agénor y Montiel, 1999).
}

terés internas a fin de desalentar el exceso de gasto en la economía. Para responder a esta inquietud estiman ecuaciones en forma reducida para el período 19931999, que derivan de un modelo de equilibrio parcial destinado a analizar la determinación conjunta de las tasas de interés real y del tipo de cambio real. Su modelo se basa en tres ecuaciones: una para los determinantes de corto plazo de la tasa de interés real, una para el dinámica de largo plazo del tipo de cambio real y la tercera para el comportamiento de los flujos de capital. $^{25}$

De acuerdo a sus estimaciones y simulaciones econométricas, los controles de los flujos de capital tienen un efecto positivo sobre la tasa ex ante de interés real interna y, en consecuencia, fueron efectivos para aumentar “... la tasa de interés real interna en el contexto de una economía abierta con escasa autonomía monetaria". ${ }^{26}$ Asimismo, encuentran que los controles producen este efecto sin crear presiones a favor de una apreciación real del peso.

\section{El marco econométrico}

Como se discute en las secciones anteriores, el enfoque basado en el diferencial de tasas de interés no cubierto es adecuado para estudiar los efectos de la regulación colombiana sobre los flujos de capital. De hecho, empleando estadísticas mensuales correspondientes al período comprendido entre enero de 1990 y diciembre de 1999, se puede estimar una ecuación en la cual los flujos de capital privado, medidos por el saldo de divisas del banco central, ${ }^{27}$ son función del

\footnotetext{
${ }^{25}$ En este trabajo, la tasa de interés se determina por la devaluación real esperada, el equivalente tributario de los encajes y la tasa de interés internacional ex ante. Las desviaciones de corto plazo respecto de la condición de paridad de largo plazo supuestamente van unidas a un exceso de oferta monetaria interna. Por su parte, el tipo de cambio se determina por factores reales de largo plazo, como la relación de precios de intercambio, los gastos del gobierno, los flujos reales de capital y una tendencia que capta el cambio tecnológico y la variación de la productividad. Finalmente, los flujos de capital se construyen como función de las diferencias de tasas de interés, incluido el equivalente tributario de los encajes.

${ }^{26} \mathrm{El}$ texto entre comillas es una cita original traducida del inglés. ${ }^{27}$ Los flujos de capital en efectivo difiere de las cuentas ordinarias de la balanza de pagos en cuanto que las exportaciones y las importaciones se registran en el momento en que se pagan, ya que es entonces cuando generan flujos en efectivo. Por lo tanto, el financiamiento del comercio se excluye de la cuenta de capitales y se torna en uno de los factores determinantes de la cuenta corriente de la balanza cambiaria. En cualquier caso, el financiamiento comercial debe ser excluido del ejercicio, puesto que se regía por una reglamentación diferente y sólo estaba parcialmente sujeto a los encajes al endeudamiento. Además, Ocampo y Tovar (1997) no encontraron evidencia de arbitraje de interés en el financiamiento comercial.
} 
diferencial de tasas de interés y otras variables. En otras palabras, puede suponerse que existe un problema de asignación de cartera que genera una solución (lineal) como la siguiente:

$$
K f=K f\left(\underset{+}{g}, A, \delta_{i}, \phi_{i}\right)
$$

donde $g$ es una variable de actividad económica, representada por las importaciones de bienes de capital; $A$ es el factor de arbitraje del diferencial de tasas de interés, incluido el efecto de los encajes sobre el endeudamiento externo, según se define en la ecuación [2] y se ilustra en el gráfico $2 ; \delta_{i}$ representa la variable ficticia utilizada para considerar el efecto sobre el volumen total de las entradas de capital inducido por las distintas regulaciones aplicadas en el período analizado ${ }^{28}$ y $\phi_{i}$ representa las variables dicotómicas utilizadas para tener en cuenta las variaciones transitorias de la oferta de flujos de capital asociada al efecto "tequila" y a las crisis asiática, rusa y brasileña. ${ }^{29}$

Los signos de la ecuación [7] muestran la relación esperada entre los flujos de capital privado y cada una de las variables explicativas. Sin embargo, la interpretación de las variables ficticias para representar los controles de los flujos de capital depende de si las regulaciones liberalizaron la cuenta de capital - como en febrero de 1992, septiembre de 1993, febrero-marzo de 1996, marzo de 1997 y enero y septiembre de 1998 - o si, por el contrario, aumentaron la severidad de los controles - como en marzo y agosto de 1994, enero de 1997 y mayo de 1997 (cuadro 1). ${ }^{30}$ En el primer caso se prevé un coeficiente positivo, que debe interpretarse como un ajuste de los acervos de endeudamiento inducidos por la liberalización, mientras que

\footnotetext{
${ }^{28}$ Otras variables que se utilizan en la literatura son las clasificaciones crediticias o medidas de exceso de gasto, con las cuales se busca captar determinantes del déficit en cuenta corriente. Aunque tal vez convenga considerarlas, resultan inadecuadas por la forma en que se construyeron las series. De hecho, autores como De Gregorio, Edwards y Valdés (2000) o Rincón (1999), partiendo de series anuales o trimestrales, han construido series mensuales que fácilmente pueden conducir a estimaciones sesgadas.

${ }^{29}$ Las variables ficticias incluidas fueron: "efecto tequila" (enero de 1995 a marzo de 1995), Asia (noviembre de 1997 a diciembre de 1997), Rusia (agosto de 1998 a noviembre de 1998) y Brasil (enero de 1999 a mayo de 1999). Además, se incluyó una variable ficticia de carácter general para el período comprendido entre noviembre de 1997 y noviembre de 1999, suponiendo que tras la crisis asiática algunas corrientes financieras dejaron de dirigirse a las economías emergentes. Sólo se reportan las variables ficticias estadísticamente significativas.

30 También se consideró una variable ficticia para captar la fuerte afluencia de capital que se produjo en diciembre de 1996, que en parte estuvo relacionada con procesos de privatización.
}

en el segundo caso se prevé un coeficiente negativo, reflejando el efecto discreto de los controles sobre las entradas de capital, más allá del captado por el diferencial de tasas de interés: $A$.

La interpretación de las variables ficticias utilizadas para el período comprendido entre agosto de 1994 y enero de 1996 merece atención especial. En las semanas anteriores a la adopción de medidas restrictivas de agosto de 1994, se registraron en el Banco de la República endeudamientos por montos significativos (que estaban sujetos a los encajes decretados en marzo de 1994), debido a que los agentes esperaban que el nuevo Presidente, que asumió el mando a comienzos de agosto, propondría que el banco central impusiera normas más severas, propuesta que probablemente éste aceptaría. Tales registros tempranos disminuyeron, sin duda, la efectividad de los controles en los primeros meses de aplicación de las nuevas restricciones. Por lo tanto, para reflejar el efecto del movimiento especulativo descrito y medir la eficacia de los controles en ese período, se utilizaron dos variables ficticias. La primera, para septiembre-diciembre de 1994, debería captar el ataque especulativo contra los controles y, en consecuencia, debería tener signo positivo, mientras que la segunda, para enero de 1995-enero de 1996, debería captar el efecto retardado de los controles y tener signo negativo.

La ecuación [7] capta el efecto de las nuevas normas por dos canales alternativos. En primer lugar, mediante el costo adicional del endeudamiento externo, que afecta los flujos de capital a través del factor de arbitraje, y, en segundo lugar, por medio del efecto discreto de la reglamentación, según se captura a través de variables ficticias. Este último efecto puede interpretarse como evidencia de sustitución imperfecta entre préstamos a plazos diferentes, debido a factores de riesgo asociados a la oferta que afectan su disponibilidad relativa.

\section{Análisis de cointegración}

Para estimar la ecuación [7], se verificó el orden de integración de las series $K f, g$ y A. Siguiendo el método de Cárdenas y Barrera (1997) y Ocampo y Tovar (1997), se utilizaron dos medidas alternativas del factor de arbitraje de intereses: una se construye usando el costo del encaje aplicable a los préstamos a 18 meses, mientras que la otra emplea dicho costo para créditos a 36 meses (gráfico 2). El cuadro 2 muestra pruebas de Dickey-Fuller aumentadas para capturar la presencia de raíces unitarias. Como se observa, en 


\begin{tabular}{|c|c|c|c|c|c|c|c|c|c|c|c|}
\hline \multirow[b]{3}{*}{ Variable } & \multirow{3}{*}{ Rezago } & \multicolumn{10}{|c|}{ Estadístico T } \\
\hline & & \multirow{2}{*}{$\begin{array}{l}\text { T-tau } \\
\text { Coefi- } \\
\text { ciente }\end{array}$} & \multicolumn{3}{|c|}{3} & \multicolumn{2}{|c|}{$\mathrm{T}-\mathrm{mu}$} & 1 & \multicolumn{3}{|c|}{$\mathrm{T}$} \\
\hline & & & $\begin{array}{l}\text { Valor } \\
\text { crítico }\end{array}$ & $\begin{array}{l}\text { Coefi- } \\
\text { ciente }\end{array}$ & $\begin{array}{l}\text { Valor } \\
\text { crítico }\end{array}$ & $\begin{array}{l}\text { Coefi- } \\
\text { ciente }\end{array}$ & $\begin{array}{l}\text { Valor } \\
\text { crítico }\end{array}$ & $\begin{array}{l}\text { Coefi- } \\
\text { ciente }\end{array}$ & $\begin{array}{l}\text { Valor } \\
\text { crítico }\end{array}$ & $\begin{array}{l}\text { Coefi- } \\
\text { ciente }\end{array}$ & $\begin{array}{l}\text { Valor } \\
\text { crítico }\end{array}$ \\
\hline \multirow{2}{*}{$\begin{array}{l}\text { Flujos de capital en efectivo } \\
\text { Dif. [flujos de capital en efectivo] }\end{array}$} & 3 & $-2,24$ & $-3,45$ & 2,72 & 6,49 & $-2,32$ & $-2,89$ & 2,71 & 4,71 & $-1,89$ & $-1,95$ \\
\hline & ] 2 & $-10,35$ & $-3,45$ & & & & & & & & \\
\hline \multicolumn{12}{|l|}{ Diferencial de tasas de interés } \\
\hline Crédito a 36 meses $(\mathrm{A} 36)^{\mathrm{b}}$ & 6 & $-3,08$ & $-3,45$ & 5,32 & 6,49 & $-1,79$ & $-2,89$ & 1,68 & 4,71 & $-1,64$ & $-1,95$ \\
\hline Dif. [A36] & 3 & $-4,84$ & $-3,45$ & & & & & & & & \\
\hline Crédito a 18 meses $(\mathrm{A} 18)^{\mathrm{b}}$ & 6 & $-2,75$ & $-3,45$ & 4,06 & 6,49 & $-1,64$ & $-2,89$ & 1,42 & 4,71 & $-1,69$ & $-1,95$ \\
\hline Dif. [A18] & 3 & $-4,84$ & $-3,45$ & & & & & & & & \\
\hline \multirow{2}{*}{$\begin{array}{l}\text { Importaciones de bienes de } \\
\text { capital }^{\text {b }} \\
\text { Dif. [Importaciones de } \\
\text { bienes de capital] }\end{array}$} & 2 & $-1,40$ & $-3,45$ & 1,16 & 6,49 & $-0,92$ & $-2,89$ & $-1,38$ & 4,71 & 0,04 & $-1,95$ \\
\hline & 1 & $-11,66$ & $-3,45$ & & & & & & & & \\
\hline
\end{tabular}

Fuente: Elaborado por los autores.

a Dif. [...] indica la primera diferencia de la variable. Valores críticos de Dickey y Fuller (1981), según figuran en Harris (1995), para una muestra de $\mathrm{T}=100$ y $5 \%$ de significación. El número de los rezagos se eligió utilizando el criterio de información bayesiano.

b Indica que no puede rechazarse la hipótesis nula de presencia de la raíz unitaria.

ninguna de las cuatro series pudo rechazarse la hipótesis nula de existencia de raíces unitarias.

Debido a la presencia de raíces unitarias en las series y para evitar regresiones espurias, las estimaciones econométricas se realizaron utilizando una estructura multivariada. ${ }^{31}$ En otras palabras, para estimar la relación lineal descrita por la ecuación [7] se utilizó el esquema de análisis de cointegración de máxima verosimilitud de Johansen. En especial, la relación estimada es la siguiente:

$$
\Delta z_{t}=\Gamma_{1} \Delta z_{t-1}+\Pi z_{t-1}+\mu+\Psi D_{t}+\varepsilon_{t}
$$

donde, $\Pi=\alpha \beta$, , siempre que $\alpha$ y $\beta$ sean matrices $(3 \mathrm{x} 1)$ que miden la velocidad de ajuste al desequilibrio y los coeficientes de largo plazo, o la relación de cointegración, respectivamente. Entretanto, $z_{t}$ es un vector (3x1) formado por las variables $K f, A$ y $g$, y $D_{t}$ es un vector formado por las variables ficticias de intervención $\delta_{i}$ y $\phi_{i}$, que controlan las variaciones de la reglamentación aplicable a los préstamos externos y las perturbaciones de la oferta que van unidas al entorno

${ }^{31}$ En realidad, es un hecho bien conocido que la combinación lineal de variables no estacionarias puede ser estacionaria y, en consecuencia, cointegrada. Como lo sugiere la literatura, lo que hay que hacer es utilizar un análisis de variables múltiples y verificar si hay presencia de vectores de cointegración. financiero internacional, respectivamente. ${ }^{32}$ Por último, $\varepsilon_{t} \sim \operatorname{niid}(O, \Sigma) .^{33}$

Los resultados se resumen en los cuadros 3 y 4 . El cuadro 3 reporta las pruebas $\lambda$-traza y $\lambda$-max para la hipótesis de rango reducido del modelo completo de autorregresión vectorial (VAR). ${ }^{34}$ Las tres primeras ecuaciones de este cuadro utilizan los diferenciales de tasas de interés, incluido el costo de los encajes para los préstamos a 36 meses, mientras que las otras tres ecuaciones usan el costo de los encajes de los préstamos a 18 meses. Según estas pruebas, en cada una de las ecuaciones estimadas se encontró una relación de cointegración entre los flujos de capital privado $K f$, los diferenciales de tasas de interés $A$ y las importaciones de bienes de capital $g$. Para fines de interpretación, el vector de cointegración o la relación de largo plazo se normaliza por el coeficiente asociado a los movimientos de

\footnotetext{
32 Tal vez algunos lectores consideren que muchas de las variables ficticias entrañan incertidumbre respecto de la especificación del modelo. Sin embargo, esta no es un punto de vista universalmente aceptado y posiblemente no lo comparten econometristas británicos como David Hendry. Agradecemos a Kenneth West este comentario. ${ }^{33}$ Véase en el apéndice A una derivación más detallada del sistema estimado.

${ }^{34}$ El número de rezagos de los modelos no restringidos de autorregresión vectorial (VAR) se eligió aplicando el criterio de información bayesiano. Además, como se muestra en el apéndice A, las estimaciones del modelo vectorial de corrección de error (VECM) utilizan este número de rezagos menos uno.
} 
CUADRO 3

Colombia: Prueba de rango de los vectores de cointegración ${ }^{a}$

\begin{tabular}{|c|c|c|c|c|c|c|c|}
\hline & Valor Eigen & L-max & Valor crítico & L-traza & Valor crítico & \multicolumn{2}{|c|}{ Hipótesis nula } \\
\hline & & & & & & $\mathrm{b}$ & $\mathrm{c}$ \\
\hline \multirow[t]{3}{*}{ Ecuación 1} & 0,4194 & 64,2 & $21,0^{\mathrm{d}}$ & 77,2 & $29,7^{\mathrm{d}}$ & $\mathrm{r}=0$ & $\mathrm{p}-\mathrm{r}=3$ \\
\hline & 0,0635 & 7,8 & 14,1 & 13,0 & 15,4 & $r=1$ & $\mathrm{p}-\mathrm{r}=2$ \\
\hline & 0,0434 & 5,2 & 3,8 & 5,2 & 3,8 & $\mathrm{r}=2$ & $\mathrm{p}-\mathrm{r}=1$ \\
\hline \multirow[t]{3}{*}{ Ecuación 2} & 0,4145 & 63,2 & $21,0^{\mathrm{d}}$ & 72,8 & $29,7^{\mathrm{d}}$ & $r=0$ & $\mathrm{p}-\mathrm{r}=3$ \\
\hline & 0,0636 & 7,8 & 14,1 & 9,6 & 15,4 & $r=1$ & $\mathrm{p}-\mathrm{r}=2$ \\
\hline & 0,0159 & 1,9 & 3,8 & 1,9 & 3,8 & $r=2$ & $\mathrm{p}-\mathrm{r}=1$ \\
\hline Ecuación 3 e/ & 0,4105 & 62,4 & $21,0^{\mathrm{d}}$ & 62,4 & $29,7^{\mathrm{d}}$ & $\mathrm{r}=0$ & $\mathrm{p}-\mathrm{r}=1$ \\
\hline \multirow[t]{3}{*}{ Ecuación 4} & 0,4072 & 61,7 & $21,0^{\mathrm{d}}$ & 74,3 & $29,7^{\mathrm{d}}$ & $r=0$ & $\mathrm{p}-\mathrm{r}=3$ \\
\hline & 0,0754 & 9,3 & 14,1 & 12,6 & 15,4 & $r=1$ & $\mathrm{p}-\mathrm{r}=2$ \\
\hline & 0,0279 & 3,3 & 3,8 & 3,3 & 3,8 & $r=2$ & $\mathrm{p}-\mathrm{r}=1$ \\
\hline \multirow[t]{3}{*}{ Ecuación 5} & 0,3990 & 60,1 & $21,0^{\mathrm{d}}$ & 70,9 & $29,7^{\mathrm{d}}$ & $\mathrm{r}=0$ & $\mathrm{p}-\mathrm{r}=3$ \\
\hline & 0,0783 & 9,6 & 14,1 & 10,8 & 15,4 & $\mathrm{r}=1$ & $\mathrm{p}-\mathrm{r}=2$ \\
\hline & 0,0102 & 1,2 & 3,8 & 1,2 & 3,8 & $r=2$ & $\mathrm{p}-\mathrm{r}=1$ \\
\hline Ecuación $6^{\mathrm{e}}$ & 0,3969 & 59,7 & $21,0^{\mathrm{d}}$ & 59,7 & $29,7^{\mathrm{d}}$ & $\mathrm{r}=0$ & $\mathrm{p}-\mathrm{r}=1$ \\
\hline
\end{tabular}

Fuente: Elaborado por los autores.

a Los vectores de cointegración se presentan en el cuadro 4. Valores críticos de Osterwald-Lenum (1992), según figuran en Harris (1995). Rezagos de todos los modelos de autorregresión vectorial (VAR): 2. Número de observaciones: 116.

b Número de vectores de cointegración.

c Número de raíces unitarias del sistema.

d Indica rechazo de la hipótesis nula a nivel de 5\% de significación estadística.

e Ecuación condicionada por exogeneidad débil. Para mayores detalles, véase el cuadro 4.

capital, de modo que la ecuación correspondiente a los flujos de capital pasa a ser:

$$
\begin{aligned}
& \text { [9] } \Delta K f_{t}=\Gamma_{11} \Delta K f_{t-1}+\Gamma_{12} \Delta A_{t-1}+\Gamma_{13} \Delta g_{t-1} \\
& +\tilde{\alpha}_{1}\left(K f_{t-1}+\left[\left(\frac{\beta_{2}}{\beta_{1}}\right) A_{t-1}+\left(\frac{\beta_{3}}{\beta_{1}}\right) g_{t-1}\right]\right)+\psi_{11} D_{t}+\varepsilon_{t}
\end{aligned}
$$

donde $\tilde{\alpha}_{1}=\alpha_{1} \beta_{1}$ mide la velocidad media de ajuste al equilibrio de largo plazo (véase más detalles en el apéndice $\mathrm{A}$ ).

Las estimaciones correspondientes a la ecuación [9] figuran en las columnas 1, 2, 4 y 5 del cuadro 4. A primera vista, ellas indican que hay una relación sólida y estadísticamente significativa entre los flujos de capital en efectivo y los diferenciales de tasas de interés, ${ }^{35}$ una relación que examinaremos detalladamente

\footnotetext{
${ }^{35}$ Los efectos también son los esperados —esto es, el aumento de la variable de actividad y del diferencial de tasas de interés tiende a incrementar los flujos de capital. Sin embargo, debido a la forma en que suelen especificarse las relaciones de cointegración de largo
}

más adelante. Además, los parámetros del término correspondiente al mecanismo de corrección de error $\tilde{\alpha}_{i}$ indican que los desequilibrios de la relación de largo plazo se ajustan rápida y exclusivamente mediante los flujos de capital en efectivo. En realidad, la falta de significación numérica y estadística de los coeficientes asociados a los diferenciales de tasas de interés y a las importaciones de bienes de capital del mecanismo de corrección de errores en las cinco primeras ecuaciones del cuadro 4 , sugiere que estas dos variables podrían considerarse débilmente exógenas al sistema. Teniendo esto presente, en el caso de estas variables se realizó una prueba sobre la razón de verosimilitud (prueba LR) sobre estos parámetros. ${ }^{36}$ Además, se realizó una prueba complementaria de la razón de verosimilitud para la exclusión de los diferenciales de tasas de interés y las importaciones de bienes de capital a partir del vector de cointegración. Los resultados de ambas

plazo (esto es, expresándolas por los vectores), en el cuadro 4 los signos resultan negativos.

36 Véase más sobre esta prueba en el apéndice A. 


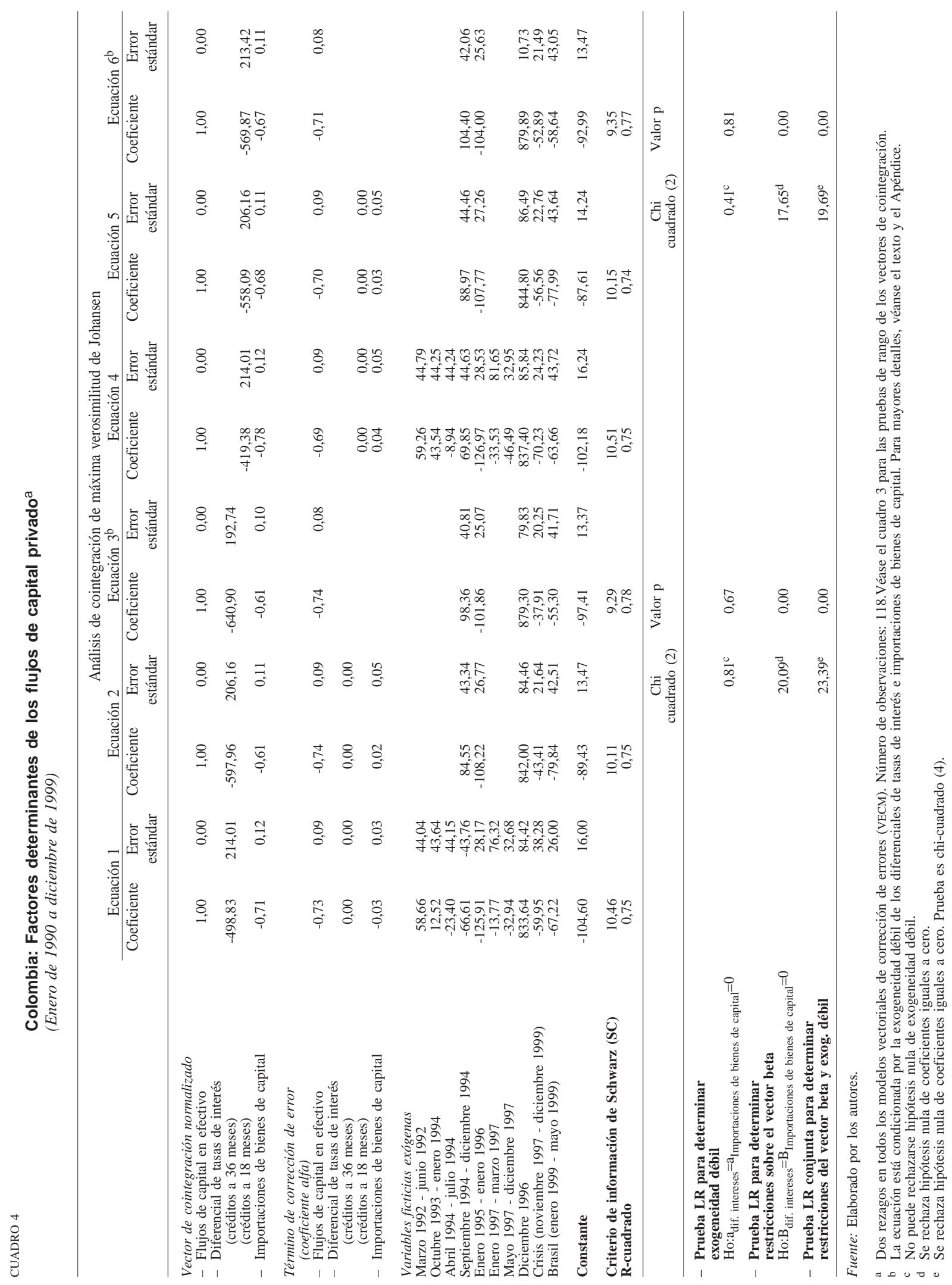


pruebas figuran en la parte inferior del cuadro 4. La primera confirma la impresión inicial de que en el caso de los flujos de capital hay que estimar un modelo condicionado - esto es, que los diferenciales de tasas de interés y las importaciones de bienes de capital deben modelarse como variables débilmente exógenas. Sin embargo, la segunda indica que no es posible excluir estas variables del vector de cointegración. ${ }^{37}$

Dados estos resultados, el nuevo sistema, condicionado por exogeneidad débil, se convierte en:

$$
\Delta K f_{t}=\tilde{\Gamma}_{0} \Delta A_{t}+\tilde{\Gamma}_{0} \Delta g_{t}+\tilde{\Gamma}_{1} \Delta Z_{t-1}
$$

$$
+\tilde{\alpha}_{1}\left(K f_{t-1}+\left[\left(\frac{\beta_{2}}{\beta_{1}}\right) A_{t-1}+\left(\frac{\beta_{3}}{\beta_{1}}\right) g_{t-1}\right]\right)+\psi_{11} D_{t}+\varepsilon_{t}
$$

Las estimaciones correspondientes a los modelos condicionados que utilizan las dos medidas alternativas de los diferenciales de tasas de interés figuran en las ecuaciones [3] y [6] del cuadro 4. De acuerdo con ellas, más de $70 \%$ del desequilibrio de largo plazo se ajusta con rezago de un mes, lo que revela que la regulación de las entradas de capital, que alteran el equilibrio de largo plazo induciendo cambios en los diferenciales de tasas de interés, influirán rápidamente en la dinámica de los flujos de capital en efectivo. Estos resultados también indican que los diferenciales de tasas de interés causan las variaciones en los flujos de capital en el sentido de Granger. En consecuencia, una reglamentación más restrictiva desencadenará una contracción pronunciada e inmediata de la afluencia de capitales. Esto significa, a su vez, que el control de los flujos de capital basado en un instrumento de precios (encajes) disminuye rápidamente las presiones sobre las variables macroeconómicas fundamentales.

Además de las estimaciones, se realizó una prueba sobre la estabilidad de los parámetros de largo plazo. El gráfico 3 muestra el comportamiento de la prueba de estabilidad del espacio de cointegración comprendido entre septiembre de 1993 y diciembre de 1999. De acuerdo con la prueba, que se graduó a escala del cuantil $95 \%$ en la distribución $\chi^{2}$ de modo que la unidad corresponde a una prueba a nivel de $5 \%$ de significancia, en las ecuaciones [3] y [6] del cuadro 4 no fue posible rechazar la hipótesis nula de estabili-

${ }^{37}$ El cuadro 4 también da cuenta de una prueba conjunta sobre restricciones sobre el vector de cointegración como de exogeneidad débil. Tal como se indica, se rechazó la hipótesis nula de restricciones conjuntas. dad de los parámetros en el período examinado (véase el apéndice). $\mathrm{Al}$ respecto, una pregunta importante se refiere a si después de las medidas de liberalización adoptadas en septiembre de 1993 aumentó la sensibilidad de los flujos de capital en efectivo a los diferenciales de tasas de interés. De hecho, Ocampo y Tovar (1997) encontraron evidencia en este sentido. Sin embargo, para efectos de la exposición, volveremos sobre este punto más adelante. Por ahora, basta con señalar que, pese a la posibilidad de que la relación de largo plazo sea objeto de un cambio estructural, la prueba sobre la estabilidad de los parámetros indica que, estadísticamente, en el período posterior a septiembre de 1993 dicha relación se mantuvo estable.

Los efectos estimados de los diferenciales de tasas de interés sobre los flujos de capital y el efecto neto atribuible a los encajes figuran en el cuadro 5. Utilizando el coeficiente de largo plazo correspondiente a los diferenciales de tasas de interés de los préstamos a 36 meses (ecuación 3), se demuestra que, de no haberse aplicado controles, la afluencia de capital habría sido bastante mayor. El efecto de estos controles fue particularmente marcado entre abril y agosto de 1994 (los flujos de capital disminuyeron en promedio 73 millones de dólares al mes), entre septiembre de 1994 y enero de 1996 (102 millones de dólares al mes) y de enero a marzo de 1997 (70 millones de dólares al mes).

Como lo indican las estimaciones del mecanismo de corrección de errores, el efecto precio de los encajes sobre el volumen de las corrientes financieras tiende a desaparecer con bastante rapidez. En consecuencia, hay que examinar otras vías a través de las cuales tales controles puedan influir en el volumen de las corrientes de capital. Las variables ficticias exógenas del cuadro 4 captan los efectos discretos de los cambios de política en la regulación. De acuerdo con los resultados, tras las reformas liberalizadoras de febrero de 1992 y septiembre de 1993 hubo ajustes del volumen de los flujos netos capital, pero los resultados a este respecto no son concluyentes (ecuaciones 1 y 4 del cuadro 4 ).

Las estimaciones también sugieren que, antes de que se adoptara una política más restrictiva, en agosto de 1994, se produjo un comportamiento especulativo que tuvo el efecto indeseable de incrementar la afluencia de capital durante los cuatro meses siguientes (más de 98 millones de dólares al mes en promedio). En todo caso, esta modificación de la política tuvo un efecto retardado, como lo indica el hecho de que entre enero de 1995 y enero de 1996 las corrientes de capital disminuyeron en más de 101 millones de dólares al mes. Así, el efecto discreto neto de estas 
GRAFICO 3

\section{Colombia: Prueba de estabilidad del espacio de cointegración}

A. Para estimaciones de ecuación de cointegración con crédito a 36 meses

(Ecuación 3 del cuadro 4)

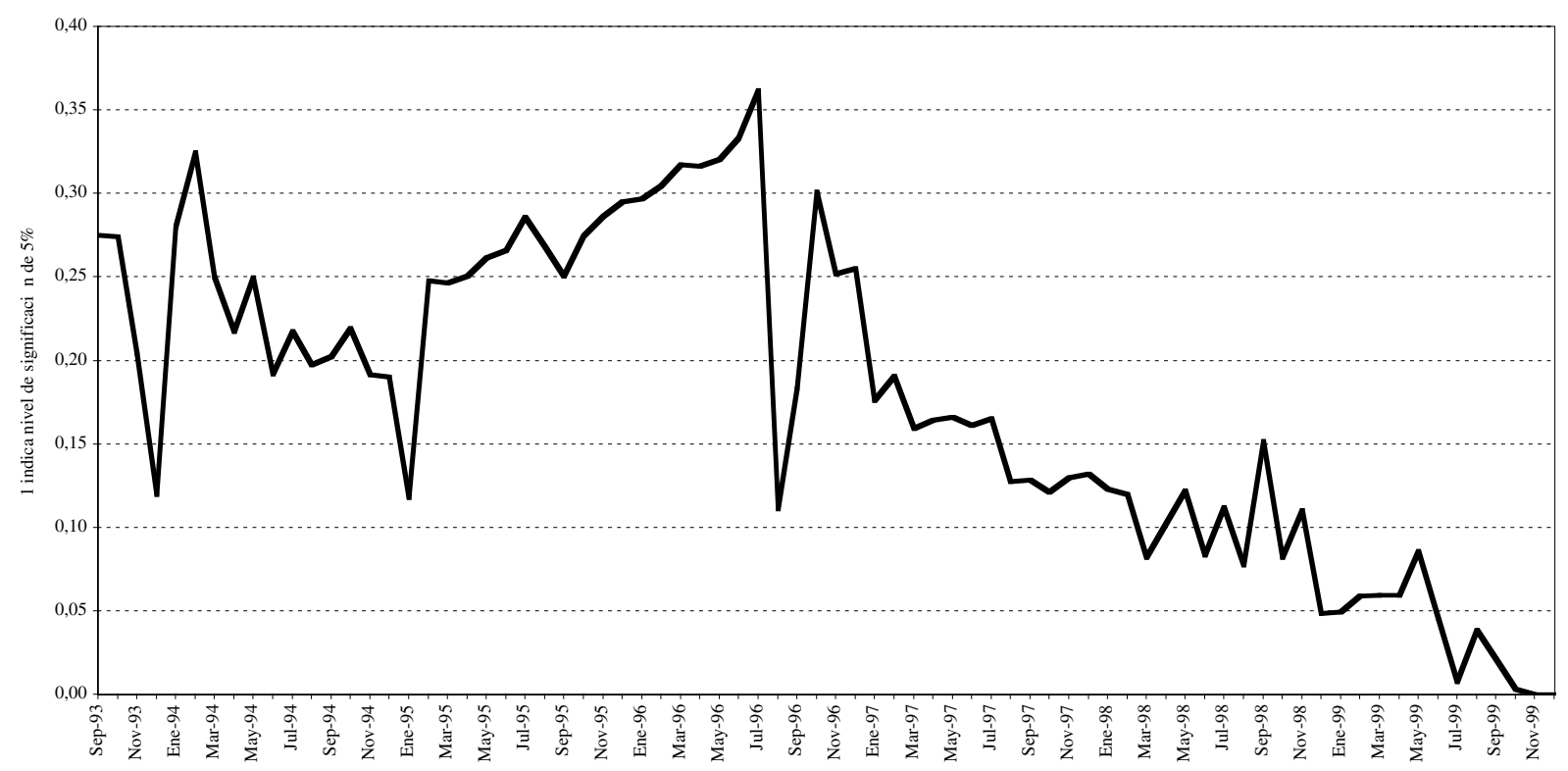

A. Para estimaciones de ecuación de cointegración con crédito a 18 meses $^{\mathrm{a}}$ (Ecuación 6 del cuadro 4)

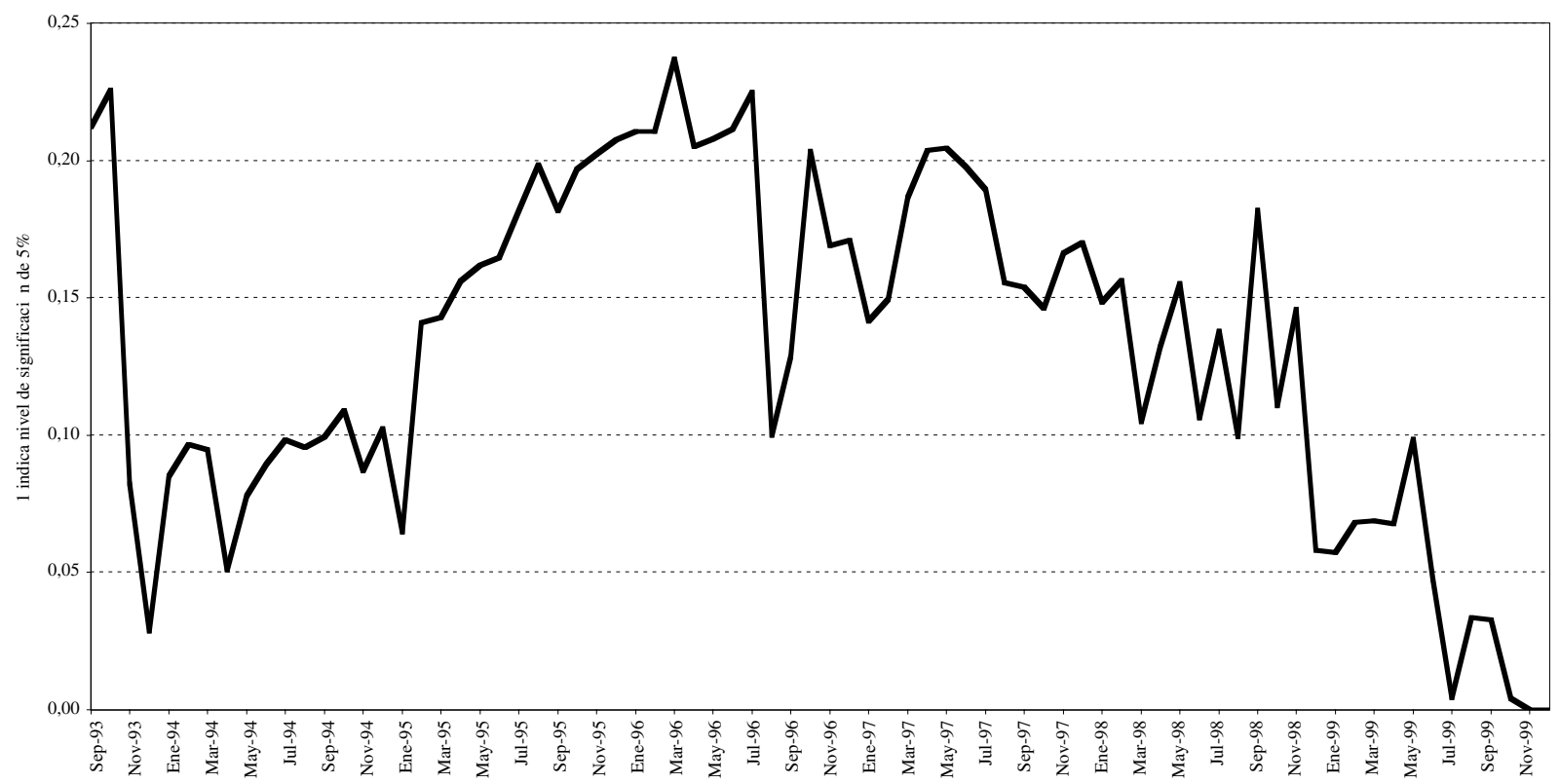

Fuente: Cálculos basados en datos del Banco de la República de Colombia.

a La prueba estadística se graduó por el cuantil de $95 \%$ en la distribución chi cuadrado, de modo que la unidad corresponde a una prueba de $5 \%$ de significación. 
Colombia: Efectos estimados de los diferenciales de tasas de interés en los flujos de capital en efectivo

(Promedios mensuales)

\begin{tabular}{|c|c|c|c|c|c|c|c|c|c|}
\hline & \multicolumn{3}{|c|}{$\begin{array}{l}\text { Diferenciales de tasas de interés } \\
\text { (porcentajes) }\end{array}$} & \multicolumn{3}{|c|}{$\begin{array}{c}\text { Flujos estimados de capital } \\
\text { en efectivo utilizando el vector } \\
\text { de cointegración estimado } \\
\text { (millones de dólares de Estados Unidos) }\end{array}$} & \multicolumn{3}{|c|}{$\begin{array}{c}\text { Flujos estimados de capital } \\
\text { en efectivo utilizando } \\
\text { estimaciones con filtro de Kalman } \\
\text { (millones de dólares de Estados Unidos) }\end{array}$} \\
\hline & $\begin{array}{l}\text { No incluye } \\
\text { encajes }\end{array}$ & $\begin{array}{l}\text { Incluye } \\
\text { encajes }\end{array}$ & $\begin{array}{l}\text { Efecto neto } \\
\text { de encajes }\end{array}$ & $\begin{array}{l}\text { No incluye } \\
\text { encajes }\end{array}$ & $\begin{array}{l}\text { Incluye } \\
\text { encajes }\end{array}$ & $\begin{array}{l}\text { Efecto neto } \\
\text { de encajes }\end{array}$ & $\begin{array}{l}\text { No incluye } \\
\text { encajes }\end{array}$ & $\begin{array}{l}\text { Incluye } \\
\text { encajes }\end{array}$ & $\begin{array}{l}\text { Efecto neto } \\
\text { de encajes }\end{array}$ \\
\hline Enero 1990 - febrero 1992 & 7,3 & & & 46,5 & & & 4,5 & & \\
\hline Marzo 1992 - septiembre 1993 & 9,3 & & & 59,4 & & & 24,9 & & \\
\hline Octubre 1993 - marzo 1994 & 13,7 & 9,8 & 3,9 & 87,9 & 62,7 & 25,1 & 53,2 & 37,8 & 15,4 \\
\hline Abril 1994 - agosto 1994 & 18,6 & 7,3 & 11,3 & 119,2 & 46,7 & 72,5 & 76,0 & 22,4 & 53,6 \\
\hline Septiembre 1994 - enero 1996 & 15,2 & $-0,8$ & 16,0 & 97,5 & $-4,8$ & 102,3 & 63,7 & $-5,7$ & 69,4 \\
\hline Febrero 1996 - diciembre 1996 & 15,5 & 6,4 & 9,2 & 99,6 & 40,7 & 58,9 & 98,5 & 43,9 & 54,6 \\
\hline Enero 1997 - marzo 1997 & 14,4 & 3,5 & 10,9 & 92,2 & 22,6 & 69,6 & 124,5 & 30,2 & 94,3 \\
\hline Abril 1997 - mayo 1997 & 11,0 & 4,2 & 6,8 & 70,5 & 27,0 & 43,5 & 91,9 & 35,9 & 56,0 \\
\hline Junio 1997 - diciembre 1997 & $-1,3$ & $-6,0$ & 4,7 & $-8,3$ & $-38,2$ & 29,9 & $-7,9$ & $-52,2$ & 44,3 \\
\hline Enero 1998 - septiembre 1998 & 4,3 & $-0,4$ & 4,7 & 27,8 & $-2,2$ & 30,0 & 27,4 & $-3,0$ & 30,4 \\
\hline Noviembre 1998 - diciembre 1999 & $-1,1$ & $-3,7$ & 2,7 & $-6,9$ & $-24,0$ & 17,1 & $-8,0$ & $-33,7$ & 25,7 \\
\hline
\end{tabular}

Fuente: Elaborado por los autores.

a Estimaciones basadas en la ecuación 3 del cuadro 4.

normas fue reducir los flujos de capital en más de 921 millones de dólares durante los 17 meses en que ellas se aplicaron, esto es, entre agosto de 1994 y enero de 1996. Además, si se agregan los efectos discretos del cambio introducido en agosto de 1994 a los inducidos por el mayor costo del endeudamiento externo (según se calcula en el cuadro 5), el efecto neto de los encajes no es nada despreciable: 2.200 millones de dólares a lo largo del período en que se aplicaron estas normas - reducción que equivale a un $27 \%$ de las reservas internacionales del banco central en diciembre de 1995.

Otras normas que tuvieron efectos discretos fueron las aplicadas en enero de 1997, cuando se introdujo el impuesto Tobin explícito, y en mayo de 1997. Sin embargo, esos efectos no fueron estadísticamente significativos.

Las estimaciones también tuvieron en cuenta los cambios discretos asociados a las crisis financieras internacionales. ${ }^{38}$ Un dato interesante es que una variable ficticia para el período comprendido entre noviembre de 1997 y diciembre de 1999 en su conjunto, que consideró el efecto oferta asociado a las perturbaciones financieras internacionales, es estadísticamente significativa y tiene efectos no despreciables. En rea-

\footnotetext{
${ }^{38}$ Con el fin de captar el entorno internacional se intentó utilizar índices de bonos latinoamericanos, pero los resultados no fueron satisfactorios.
}

lidad, las estimaciones sugieren que, en promedio, las entradas mensuales de capital a Colombia cayeron en 38 millones de dólares. También revelan la existencia de un efecto adverso y significativo de "vecindario", asociado a la crisis brasileña, que entre enero y mayo de 1999 redujo las entradas mensuales de capital en efectivo en más de 55 millones de dólares. En consecuencia, desde finales de 1997 la afluencia neta de capital a la economía colombiana disminuyó en un monto cercano a los 807 millones de dólares debido al contagio internacional.

\section{Efectos transitorios y discretos de los diferen- ciales de tasas de interés}

Como ejercicio alternativo para estimar los efectos de los controles sobre los flujos de capital, se aplicó un filtro de Kalman a la ecuación [7]. El gráfico 4, sección $\mathrm{A}$, muestra los efectos transitorios y discretos de los diferenciales de tasas de interés sobre los flujos de capital para los préstamos a 36 meses. Los primeros van unidos a las variaciones que experimentan los diferenciales de las tasas de interés como consecuencia de cambios en el costo de los encajes, mientras que los segundos guardan relación con ajustes en el volumen de las corrientes de capital. Como se muestra, al tornarse más restrictiva la reglamentación, se logró reducir la afluencia de capital, especialmente en agosto de 
GRAFICO 4

Colombia: Efectos estimados de los controles de los flujos de capital basados en el precio

A. Efectos transitorios y discretos de los diferenciales de tasas de interés (Incluye costo de encajes)

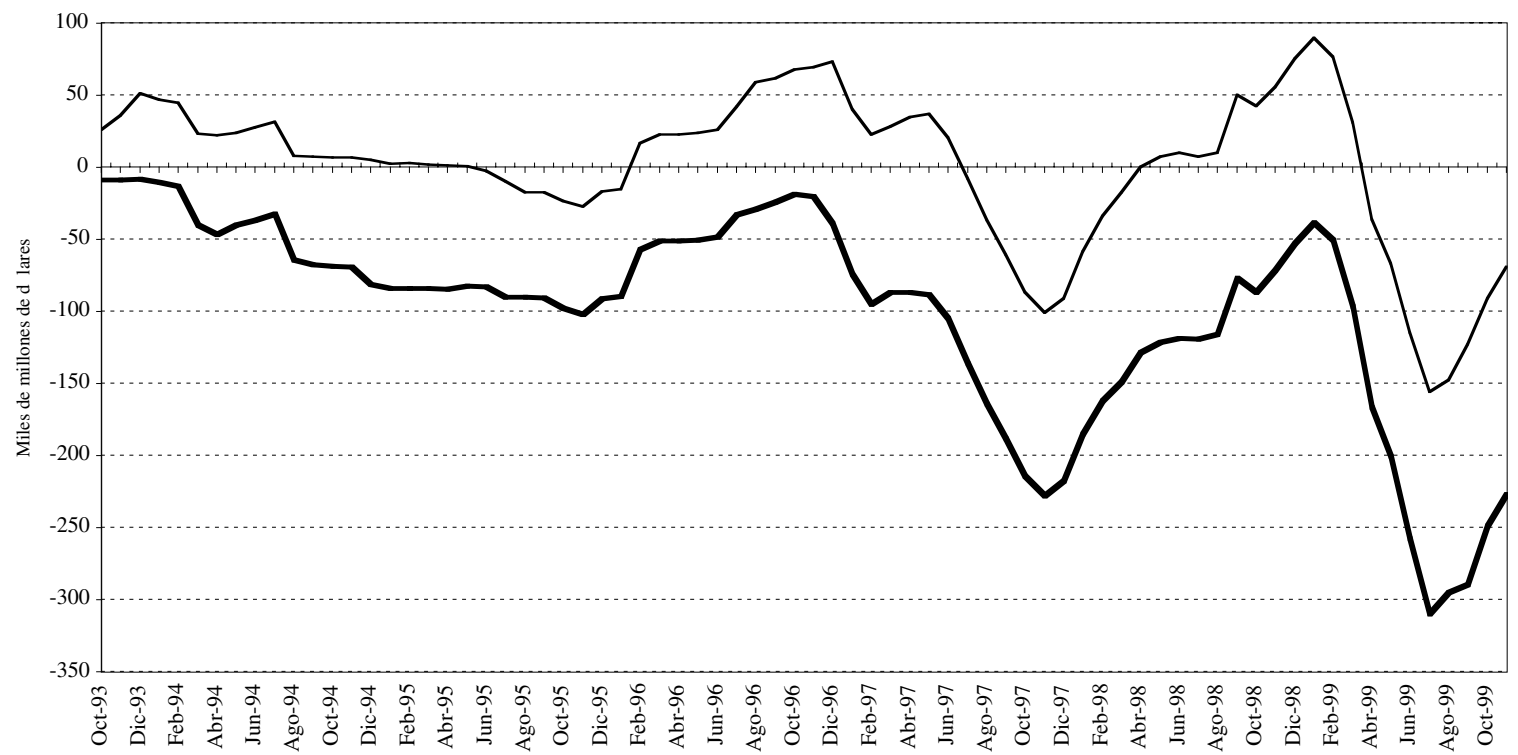

- Excluye efecto discreto ( $\mathrm{t}$ rmino constante) - Incluye efecto discreto ( $\mathrm{t}$ rmino constante)

B. Efectos generales de los diferenciales de tasas de interés (Con y sin costo de los encajes)

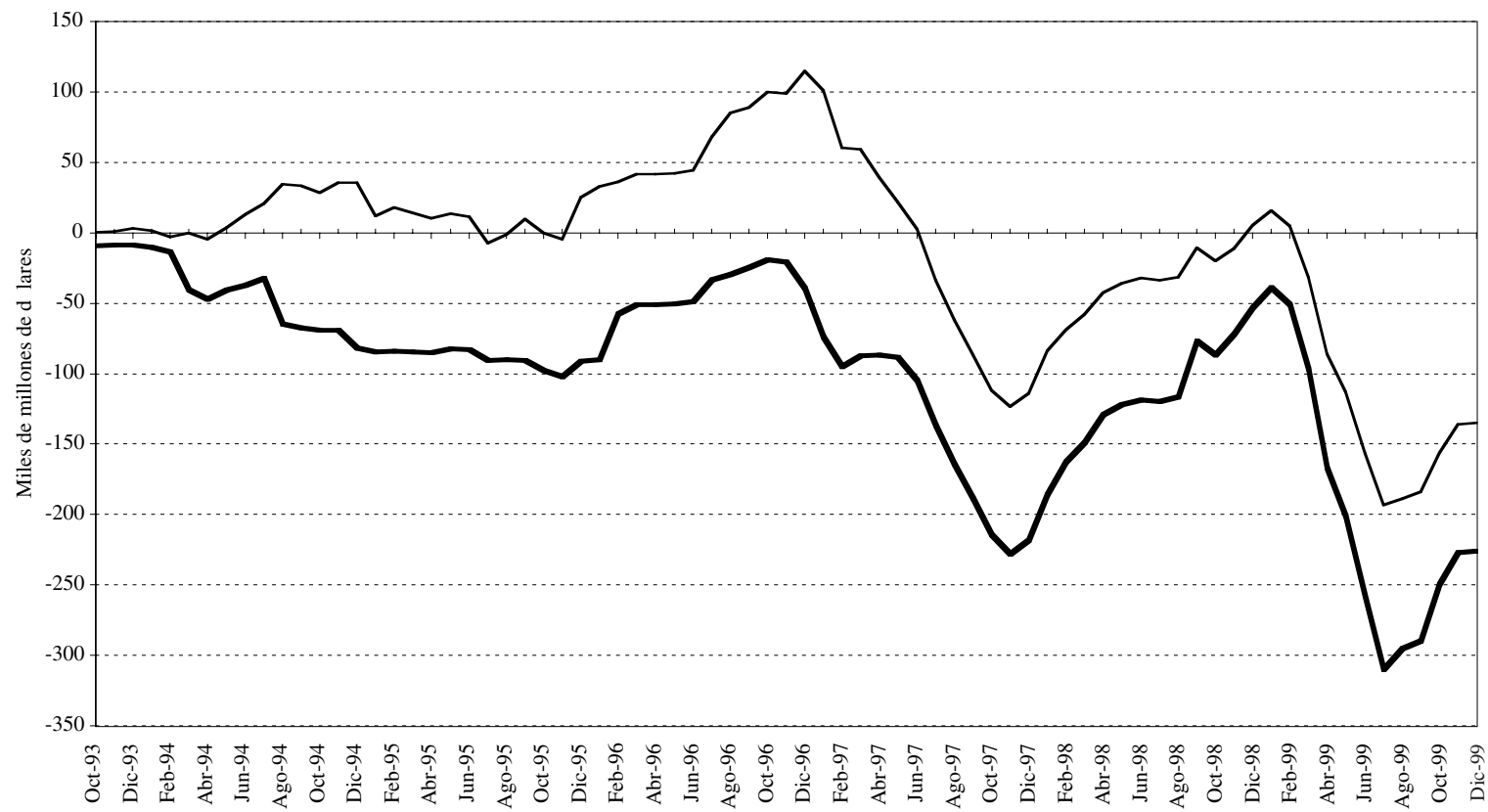

$$
\text { Excluye costo de los encajes } \quad \text { Incluye costo de los encajes }
$$

Fuente: Cálculos basados en datos del Banco de la República de Colombia. 
1994, y enero y mayo de 1997. Y cuando las normas se flexibilizaron, en febrero de 1996 y enero de 1998, los flujos de capital aumentaron. Como se observa en el gráfico 4, sección B, donde se comparan los efectos estimados de los diferenciales de tasas de interés incluyendo y excluyendo el costo de los encajes, el efecto de esos diferenciales sobre los flujos de capital puede atribuirse principalmente al control de los flujos, ya que la diferencia entre ambas series obedece principalmente al costo de los encajes.

Además, cuando se utiliza el método del filtro de Kalman, la dinámica de los efectos estimados de los diferenciales de tasas de interés se asemeja a la estimada cuando se utiliza la metodología de cointegración de Johansen (cuadro 5). Sin embargo, cabe señalar que antes de enero de 1997 los efectos netos de los encajes parecen más débiles si se utiliza el filtro de Kalman que aplicando el método de la cointegración, y después de esa fecha, levemente más vigorosos.

Estos resultados indican que los controles a los flujos de capital fueron eficaces para reducir las entradas de capital, debido al mayor costo de los préstamos de corto plazo y a los efectos discretos de las normas aplicadas, que se relacionan con la sustitución imperfecta de créditos que tienen plazos de vencimiento diferentes. En especial, los severos controles establecidos en agosto de 1994 (con un rezago relacionado con el comportamiento especulativo observado antes de que se aplicaran las nuevas normas) y las restricciones introducidas en enero y mayo de 1997 tuvieron los efectos esperados. Los resultados también indican que tras las medidas de liberalización de febrero de 1992 y septiembre de 1993 pueden haberse producido ajustes transitorios en los volúmenes de los flujos netos de capital.

\section{Pruebas de cambio estructural}

Un aspecto importante al analizar el efecto de los controles de capital basado en un instrumento de precios (el encaje) es que fueron concebidos para países que optan por integrarse a los mercados financieros internacionales. En consecuencia, una de las cuestiones fundamentales que hay que resolver es si la transición del antiguo sistema de control de cambios al de un esquema de encajes significó una liberalización efectiva de los flujos de capital o si no tuvo ese efecto. Dicho de otra manera, una liberalización efectiva debería reflejar una mayor sensibilidad de los flujos de capital en efectivo a los incentivos generados por el arbitraje de intereses. El cuadro 6 muestra los resulta- dos de un análisis de regresión simple mediante el método de mínimos cuadrados ordinarios ${ }^{39}$ para captar la variación de la sensibilidad de los flujos de capital al arbitraje de intereses tras la reforma del sistema de cuenta de capital de septiembre de 1993. La principal diferencia entre este procedimiento y el de cointegración que se presentó anteriormente es que ambas medidas de los diferenciales de tasas de interés interactúan con dos variables ficticias. Una de ellas capta el período anterior a la liberalización (enero de 1990 a septiembre de 1993) y la otra, el período posterior a ella (octubre de 1993 a diciembre de 1999).

El cuadro 6 presenta seis regresiones diferentes. Las principales diferencias entre ellas corresponden a los diferenciales de tasas de interés utilizados (créditos a 18 meses o a 36 meses, respectivamente). Además, en cada caso se informa de tres ejercicios diferentes. Las ecuaciones [1] y [2] del cuadro corresponden a regresiones simples, en que no se consideran los ajustes en el volumen de los flujos netos de capital asociados a cambios de política o al entorno internacional con posterioridad a crisis financieras. Las ecuaciones restantes contienen especificaciones diferentes que sí toman en cuenta estos factores. Además, para cada regresión se realizó una prueba de Chow con el fin de captar el cambio estructural en la sensibilidad de los flujos de capital a los diferenciales de tasas de interés reportados.

Los resultados revelan que tras la reforma introducida en septiembre de 1993 aumentó apreciablemente la sensibilidad de los flujos de capital en efectivo al arbitraje de intereses, lo que indica que efectivamente sirvió para liberalizar la cuenta de capital. Las distintas especificaciones utilizadas ilustran la solidez de esta conclusión. En efecto, la prueba de Chow para verificar el cambio estructural indica que en todos los casos se rechaza la hipótesis nula de que los flujos de capital fueron igualmente sensibles a los diferenciales de las tasas de interés tanto antes como después de las reformas de 1993. Además, los resultados revelan que si bien a partir de septiembre de 1993 los flujos de capital fueron extremadamente sensibles a los diferenciales de tasas de interés, en el período anterior a la liberalización este arbitraje de intereses no es estadísticamente significativo, como se refleja en los $t$ estadísticos implícitos en los coeficientes estimados.

\footnotetext{
${ }^{39}$ Debido a que las series están cointegradas, no hay riesgo de regresión espuria.
} 


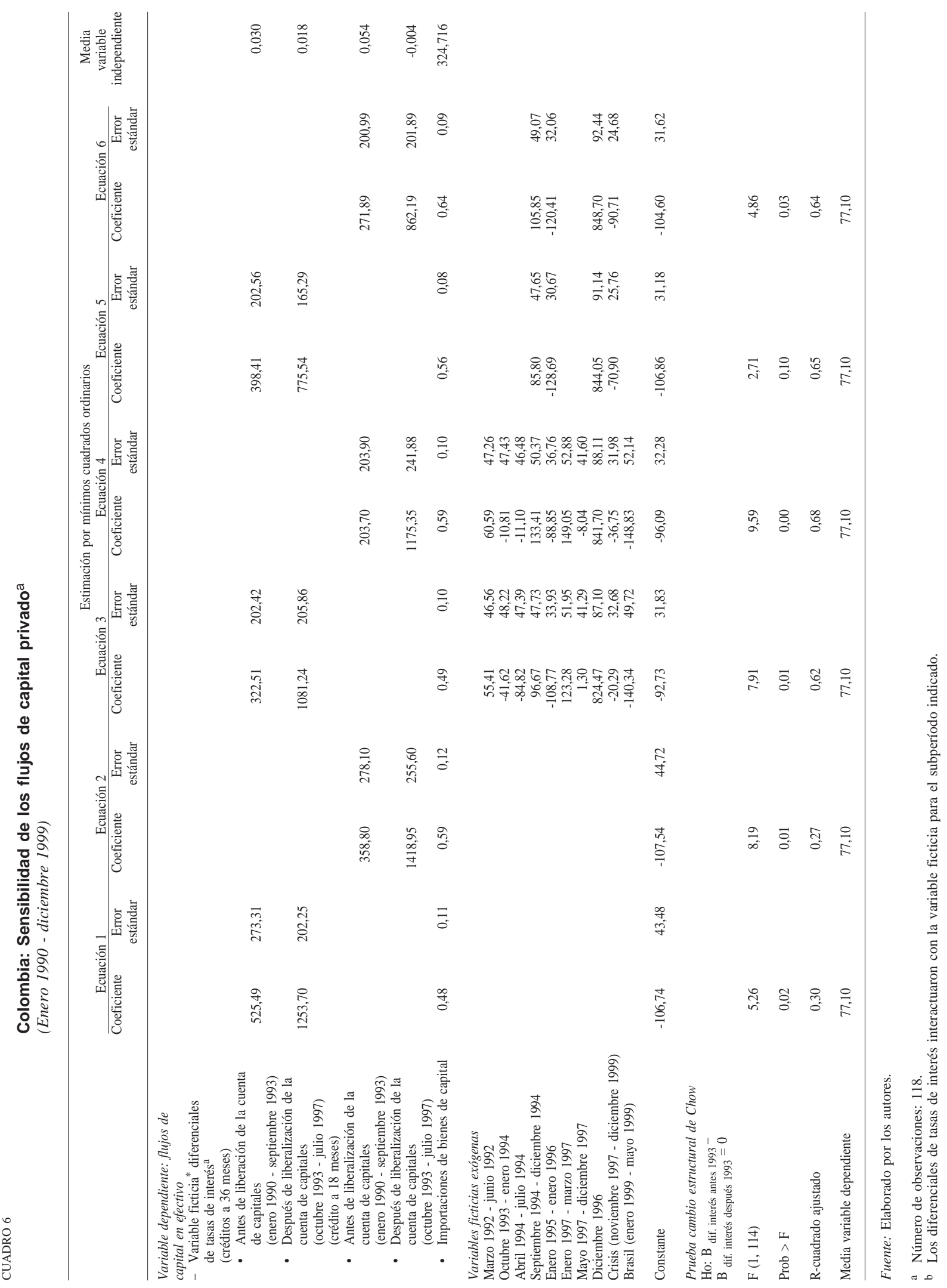


GRAFICO 5

\section{Colombia: Estructura de vencimientos de la deuda externa privada}

A. Saldo de la deuda externa privada

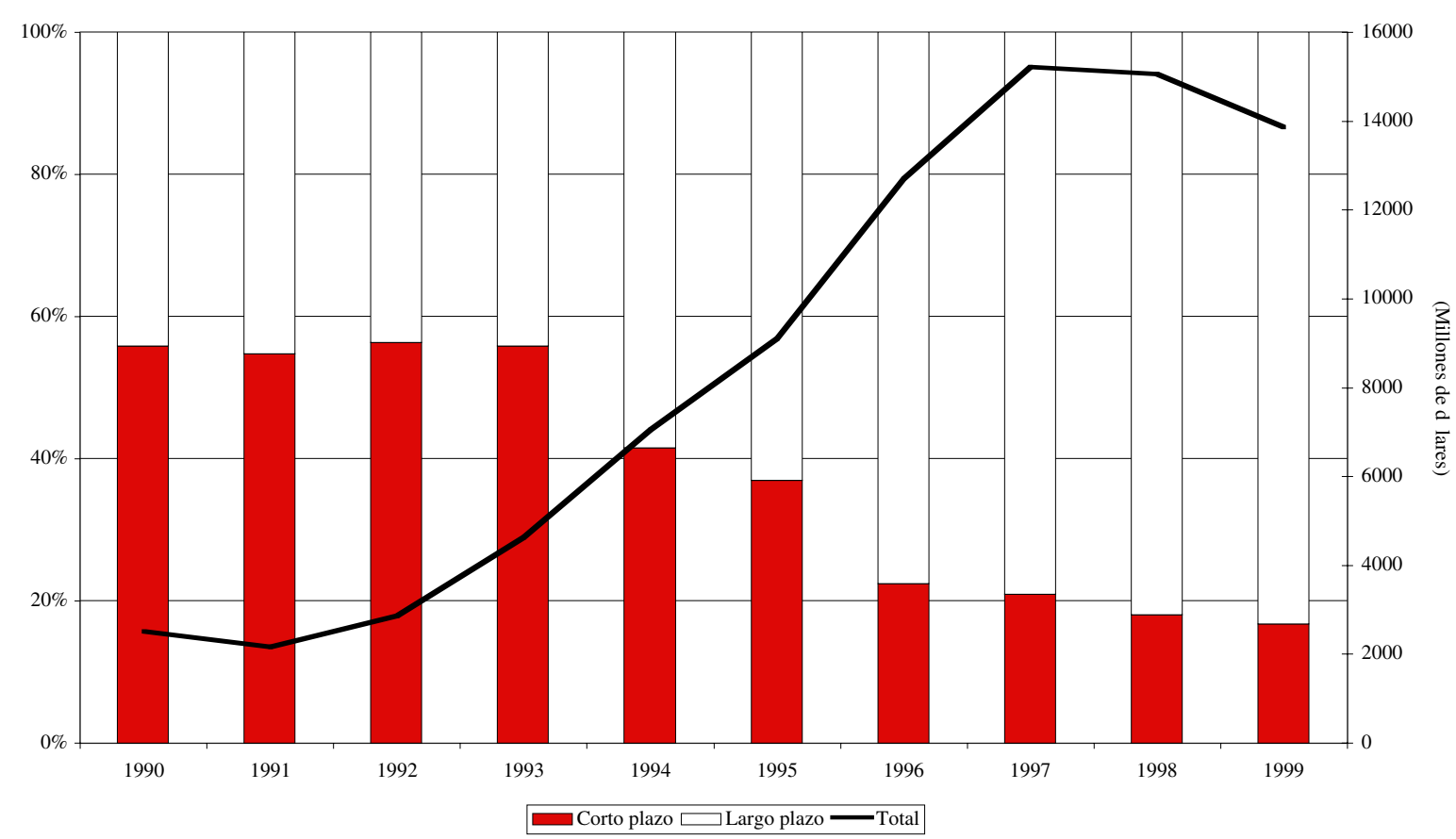

B. Registros de préstamos externos de instituciones financieras internacionales según vencimiento (Porcentaje del total)

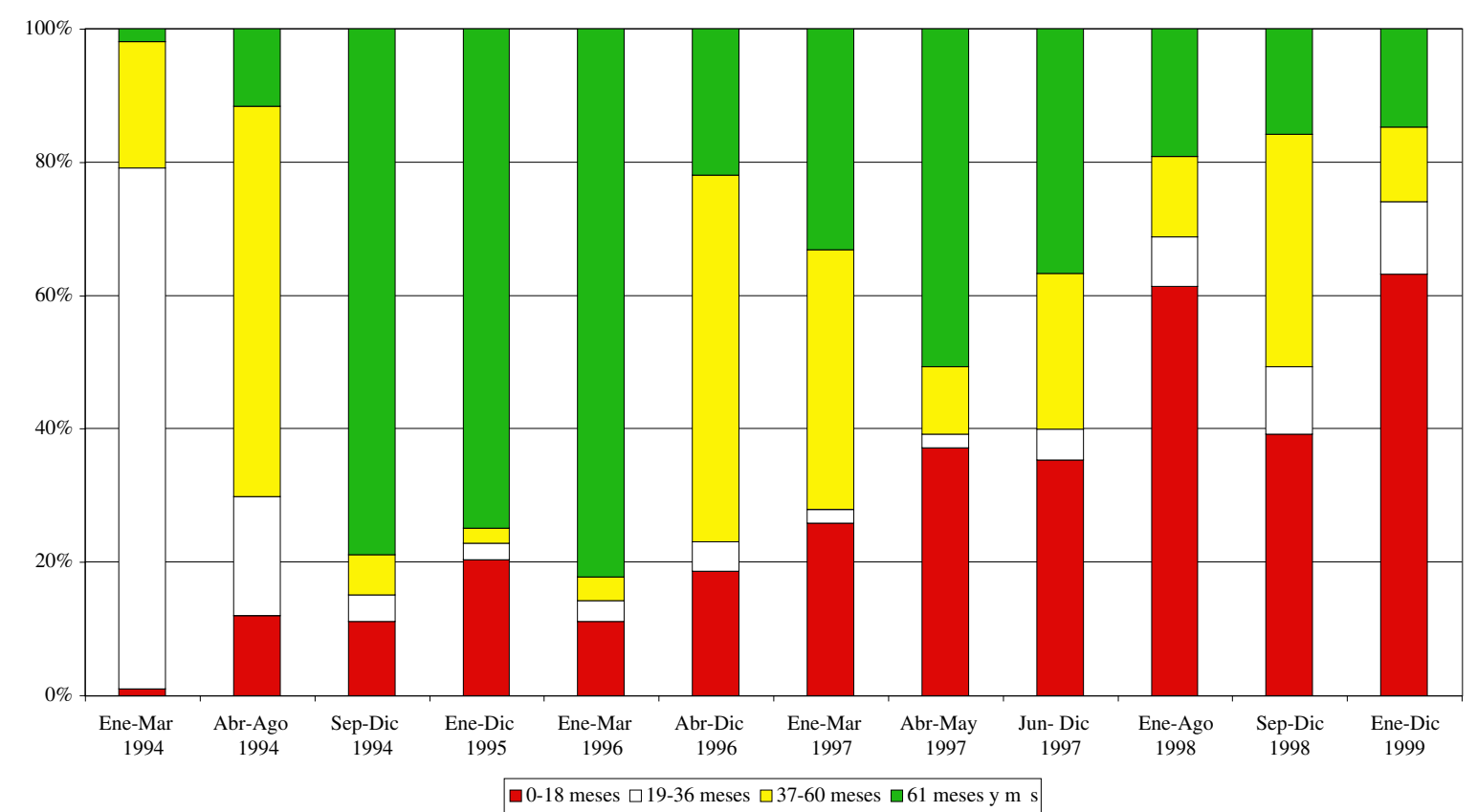

Fuente: Cálculos basados en datos del Banco de la República de Colombia. 


\section{La estructura de vencimientos de la deuda externa}

Los resultados econométricos presentados muestran que los controles de capital influyeron de manera significativa en el volumen de entradas netas de capital. Al evaluar la eficacia de estos controles es preciso determinar también si dieron lugar a que mejorara la estructura de vencimientos de la deuda externa colombiana. Esto tiene particular importancia porque, como se ha visto, la literatura sobre las crisis financieras ha puesto de relieve que la excesiva dependencia de créditos de corto plazo aumenta la vulnerabilidad del país y su exposición a estas crisis. Basándose en datos anuales, el gráfico 5 muestra, en su sección A, la estructura de vencimientos de la deuda externa privada de $\mathrm{Co}-$ lombia. Tal como allí se indica, durante el decenio de 1990 la participación de la deuda colombiana de corto plazo en la deuda privada total del país cayó fuertemente: de cerca de $60 \%$ a menos de $20 \%$. Esta drástica reducción se logró entre 1994 y 1998, período que coincide con la aplicación intensiva de los encajes sobre los flujos de capital. Es más, la estabilidad de la proporción de la deuda de corto plazo observada después de 1997 sugiere que las normas aplicadas en mayo

\section{V}

\section{Conclusiones}

En el presente trabajo se ha examinado la efectividad de las regulaciones o controles a los ingresos de capitales basados en un instrumento de precios (el encaje a los ingresos de capital) que se aplicaron en Colombia en el decenio de 1990. Sus efectos se captan de dos maneras diferentes. En primer lugar, a través del diferencial de tasas de interés, que refleja el mayor costo del endeudamiento externo; en segundo término, a través de los efectos discretos de los cambios del sistema regulatorio, que pueden relacionarse básicamente con la sustitución imperfecta entre préstamos de corto y de largo plazo. ${ }^{41}$

\footnotetext{
${ }^{40}$ Es importante tener presente que los préstamos de 0 a 18 meses corresponden fundamentalmente al financiamiento de importaciones y exportaciones, que desde marzo de 1996 no ha estado sujeto a reserva obligatoria.
}

de 1997, que impusieron un encaje en pesos al endeudamiento externo con todo tipo de vencimientos, no fue un sustituto perfecto del sistema de regulación previo, que exigía un depósito en dólares cuando se trataba de créditos externos con plazos inferiores a un mínimo determinado. La evidencia que se ofrece en seguida respalda esta conclusión.

En la sección B del gráfico 5 se presenta información adicional sobre la influencia que ha tenido el sistema de encajes sobre la estructura de vencimientos de la deuda externa, basándose en promedios mensuales de préstamos en moneda extranjera otorgados por instituciones financieras y registrados en el banco central. ${ }^{40}$ Allí se observa que las normas impuestas en marzo y agosto de 1994 influyeron marcadamente en la estructura de vencimientos de los créditos externos, cuyo registro revela una tendencia a desplazarse hacia préstamos de mayor plazo. Asimismo, es evidente que políticas de liberalización aplicadas a comienzos de 1996 desplazaron la estructura de vencimientos hacia plazos menores, mientras que políticas restrictivas que se adoptaron en enero y marzo de 1997 tuvieron el efecto contrario. Finalmente, las medidas adoptadas en mayo de 1997 tuvieron efectos intermedios.
Los resultados de los ejercicios econométricos respaldan la conclusión de que las entradas de capital son sensibles a los diferenciales de tasas de interés y, en consecuencia, de que en Colombia la regulación de los flujos de capital efectivamente redujo el volumen de las corrientes de capital. Además, la información presentada indica que esta regulación mejoró la estructura de vencimientos de la deuda externa colombiana. Los resultados también confirman que la modificación del régimen de cuenta de capital efectuada en septiembre de 1993 tuvo efectivamente efectos liberalizadores,

\footnotetext{
41 Varios estudios sobre Chile, así como el de Cárdenas y Barrera (1997) sobre Colombia, sostienen que el control de los flujos de capital ha servido para modificar la estructura de vencimientos de la deuda externa, pero no para alterar el volumen total de las entradas de capital. Esta interpretación parece ser poco coherente, puesto que parte de la base de que los flujos de corto y de largo plazo son sustitutos perfectos.
} 
puesto que aumentó la sensibilidad de los flujos de capital a los incentivos para el arbitraje de intereses.

La evidencia econométrica también indica que los encajes no tuvieron los mismos efectos después de que en mayo de 1997 se reemplazara el depósito en dólares para préstamos a plazos inferiores a un determinado mínimo, por un encaje uniforme expresado en pesos que no guardaba relación con el plazo de vencimiento del préstamo. De lo dicho se infiere que este último sistema no fue un sustituto perfecto de la regulación anterior. En especial, el sistema que se aplicaba antes de mayo de 1997 tuvo efectos más pronunciados sobre la estructura de vencimientos de los créditos externos. Además, el sistema de encajes en dólares tenía un interesante efecto estabilizador en el costo del endeudamiento externo frente a las fluctuaciones del tipo de cambio nominal, efecto que se perdió con el sistema basado en encajes en pesos.

En general, el análisis sugiere que los controles sobre los flujos de capital basados en un instrumento de precios efectivamente cumplen una doble función de política cuando un país enfrenta una abundancia de capitales. Por una parte, permiten que las autoridades ejerzan un mayor control monetario y cambiario cuan-

APENDICE

Siguiendo a Hansen y Juselius (1995), supóngase el siguiente modelo de autorregresión vectorial p-dimensional del tipo:

[A.1] $z_{t}=A_{1} z_{t-1}+\ldots+A_{k} z_{t-k}+\mu+\Psi D_{t}+\varepsilon_{t} \quad \mathrm{t}=1, \ldots, \mathrm{T}$.

en que $z_{\mathrm{t}}$ es un vector $p \times 1$ de las variables estocásticas, $z_{t \text { - }}$ ${ }_{\mathrm{k}+1}, \ldots, z_{0}$ son valores fijos, $\varepsilon_{1}, \ldots, \varepsilon_{\mathrm{t}}$ son niid $(0, \Sigma)$ y $D_{\mathrm{t}}$ es un vector de las variables no estocásticas, tales como las variables ficticias de intervención.

Dado este modelo de autorregresión vectorial no restringido que involucra $k$ rezagos de $z_{t}$, puede transformarse en un modelo vectorial de corrección de error:

$$
\begin{gathered}
\text { [A.2] } \Delta z_{t}=\Gamma_{1} \Delta z_{t-1}+\ldots+\Gamma_{k-1} \Delta z_{t-k+1}+\Pi z_{t-k}+\mu+\Psi D_{t}+\varepsilon_{t} \\
\varepsilon_{t} \sim \operatorname{niid}(O, \Sigma)
\end{gathered}
$$

La hipótesis de cointegración de la ecuación [A.2] puede expresarse como prueba de rango reducido de la matriz-П:

$$
H_{o}(r): \Pi=\alpha \beta
$$

donde $\alpha$ y $\beta$ son matrices $p x r$ de rango completo y $r$ indica el número de vectores de cointegración. Además, la hipótesis $H_{o}(r)$ implica que el proceso $\Delta \mathrm{z}_{\mathrm{t}}$ es estacionario, $\mathrm{z}_{\mathrm{t}}$ es no estacionario, pero $\beta^{\prime} z_{t}$ es estacionario. do están sometidas a fuertes presiones por la afluencia de capitales. Este efecto ha sido corroborado en la investigación paralela de Villar y Rincón (2003), mediante la aplicación de un método diferente. Por otra parte, la regulación basada en un instrumento de precios también constituye una "política de pasivos" eficaz que mejora la estructura de vencimientos de las obligaciones externas, con lo cual reduce los riesgos de liquidez.

Este doble efecto convierte a los controles descritos en un mecanismo de política aconsejable para reducir la vulnerabilidad de un país a la reversión súbita de las entradas de capital. Realza aún más la conveniencia de utilizar dichos controles el hecho de que son fáciles de aplicar, no discrecionales y de carácter preventivo (prudencial), al imponer sanciones más severas a las obligaciones de corto plazo en moneda extranjera. ${ }^{42}$

Finalmente, cabe destacar que, no obstante su efectividad para restringir las entradas de capital y mejorar la estructura de la deuda externa, los controles de capital basados en un instrumento de precios no sustituyen la aplicación de políticas macroeconómicas razonables ni de aquellas destinadas a mejorar la regulación prudencial y la supervisión de los sistemas financieros nacionales.

En nuestro caso, de acuerdo con la ecuación [8], $z_{\mathrm{t}}$ es un vector $3 \mathrm{x} 1$ formado por las variables $K f$, A y g, mientras que $D_{\mathrm{t}}$ son las variables ficticias de intervención $\delta_{i}$ y $\lambda_{i}$ que controlan los cambios de la regulación aplicable al endeudamiento externo y a perturbaciones de la oferta como las crisis "tequila", asiática, rusa y brasileña, respectivamente.

Para comprender la interpretación del modelo, conviene ampliar algunos términos. Suponiendo, para mayor facilidad, que no hay componentes determinísticos y que hay un solo vector de cointegración (esto es, $r=1$ ), puede expresarse de la siguiente manera:

$$
\Pi z_{t-1}=\left[\begin{array}{c}
\alpha_{1} \\
\alpha_{2} \\
\alpha_{3}
\end{array}\right]\left[\begin{array}{lll}
\beta_{1} & \beta_{2} & \beta_{3}
\end{array}\right]\left[\begin{array}{c}
K f \\
A \\
g
\end{array}\right]=\left[\begin{array}{c}
\alpha_{1} \\
\alpha_{2} \\
\alpha_{3}
\end{array}\right]\left[\beta_{1} K f+\beta_{2} A+\beta_{3} g\right]_{t-1}
$$

En consecuencia, se puede reformular todo el sistema como:

$$
\left[\begin{array}{c}
\Delta K f_{t} \\
\Delta A_{t} \\
\Delta g_{t}
\end{array}\right]=\Gamma_{1}\left[\begin{array}{c}
\Delta K f_{t-1} \\
\Delta A_{t-1} \\
\Delta g_{t-1}
\end{array}\right]+\left[\begin{array}{c}
\alpha_{1} \\
\alpha_{2} \\
\alpha_{3}
\end{array}\right]\left[\begin{array}{lll}
\beta_{1} & \beta_{2} & \beta_{3}
\end{array}\right]\left[\begin{array}{c}
K f \\
A \\
g
\end{array}\right]_{t-1}+\left[\begin{array}{c}
\varepsilon_{1 t} \\
\varepsilon_{2 t} \\
\varepsilon_{3 t}
\end{array}\right]
$$

\footnotetext{
42 Véase en Ocampo (2003a) una comparación de estos controles basados en un instrumento de precios con los controles cuantitativos, como los que se aplicaron en Malasia durante la crisis asiática.
} 
En general, conviene normalizar el vector de cointegración por la variable que interesa, que en nuestro caso son los flujos de capital privado, $K f$. Esto se realiza simplemente multiplicando el vector $\beta$ por $1 / \beta_{1}$. Por esta razón, $\Delta K f_{t}$, la ecuación que interesa, puede formularse en la forma de corrección de error descrita por la ecuación [A.2]:

$$
\begin{gathered}
\Delta K f_{t}=\Gamma_{11} \Delta K f_{t-1}+\Gamma_{12} \Delta A_{t-1}+\Gamma_{13} \Delta g_{t-1} \\
+\tilde{\alpha}_{1}\left(K f_{t-1}+\left[\left(\frac{\beta_{2}}{\beta_{1}}\right) A_{t-1}+\left(\frac{\beta_{3}}{\beta_{1}}\right) g_{t-1}\right]\right)+\varepsilon_{t}
\end{gathered}
$$

donde $\tilde{\alpha}_{1}=\alpha_{1} \beta_{1}$.

La relación de cointegración A.4 (ecuación 9 del texto) es una serie estacionaria que se interpreta como relación de equilibrio de largo plazo entre las tres variables $K f, A$ y $g$. Si $\beta^{\prime} z_{t-1} \neq 0$, se interpreta como error del equilibrio a largo plazo. Por otra parte, $\tilde{\alpha}_{1}$, que se denomina loading, mide la velocidad media de ajuste o convergencia hacia el equilibrio de largo plazo.

Este marco analítico permite probar si una variable es débilmente exógena. Por ejemplo, se dice que la variable que representa las importaciones de bienes de capital, $g$, es débilmente exógena respecto de $\beta$ si $\alpha_{3}=0$ (véase la ecuación A.3) y en consecuencia entraña que la ecuación $\Delta g_{t}$ no contiene información sobre los parámetros de largo plazo $\beta$. En general, conviene condicionar el modelo a variables débilmente exógenas como manera de mejorar sus propiedades estocásticas. Además, es probable que el resto del sistema tenga mejor comportamiento estadístico (véanse Hansen y Juselius, 1995; Enders, 1995; Harris, 1995).

\section{Pruebas utilizadas}

La comprobación de la constancia de $\beta$ es una comprobación de la hipótesis

$$
\mathrm{H}_{\beta_{\tau}}: \tilde{\beta} \in \operatorname{sp}\left(\beta_{\tau}\right) \quad \tau=\mathrm{T}_{0}, \ldots, \mathrm{T} .
$$

donde $\tilde{\beta}$ es una matriz conocida. En nuestro caso, $\tilde{\beta}$ es el vector de cointegración estimado en las ecuaciones [3] y [6] del cuadro 4.

La estadística de la prueba es dada por:

$$
\begin{aligned}
-2 \ln \left(Q\left(\mathrm{H}_{\beta_{\tau}} \mid \hat{\beta}(\tau)\right)\right) & =\tau \sum_{i=1}^{r}\left(\ln \left(1-\hat{\rho}_{i}(\tau)\right)-\ln \left(1-\hat{\lambda}_{i}(\tau)\right)\right. \\
\tau & =\mathrm{T}_{0}, \ldots, \mathrm{T}
\end{aligned}
$$

donde $\hat{\rho}_{i}(\tau)$ son las soluciones de:

$$
\text { [A.7] }\left|\rho \tilde{\beta} S_{k k}(\tau) \tilde{\beta}-\tilde{\beta} S_{k 0}(\tau) S_{00}^{-1}(\tau) S_{0 k}(\tau) \tilde{\beta}\right|=0 \quad \tau=\mathrm{T}_{0}, \ldots, \mathrm{T} \text {. }
$$

y $\hat{\lambda}_{i}(\tau)$ son los $r$ valores de característicos más grandes en el problema de valores característicos no restringidos:

$$
\text { [A.8] }\left|\lambda S_{k k}(\tau)-S_{k 0}(\tau) S_{00}^{-1}(\tau) S_{01}(\tau)\right|=0 \quad \tau=\mathrm{T}_{0}, \ldots, \mathrm{T} .
$$

La estadística de la prueba [A.6] se distribuye asintóticamente como $\chi^{2}$ con $\left(d_{k}-r\right) r$ grados de libertad (Hansen y Juselius, 1995). En nuestro caso, $d_{k}=5$ (tres variables, una constante y la fila para las variables determinísticas) y $r=1$ (número de vectores de cointegración); por lo tanto, la estadística de la prueba se distribuye como $\chi^{2}(4)$.

(Traducido del inglés)

\section{Bibliografía}

Agénor, P. y P. Montiel (1999): Development Macroeconomics, segunda edición, Princeton, New Jersey, Princeton University Press.

Agosin, M. y R. Ffrench-Davis (1996): Managing capital inflows in Latin America, en M. ul Haq, I. Kaul e I. Grunberg (comps.), The Tobin Tax: Coping with Financial Volatility, Nueva York, Oxford University Press.

(1999): Capital flows in Chile: from the tequila to the Asian crises, Journal of International Development, vol. 11, $\mathrm{N}^{\mathrm{o}} 1$, Sheffield, University of Sheffield, enero-febrero.

Budnevich, C. y G. Le Fort (1997): Capital Account Regulations and Macroeconomic Policy: Two Latin American Experiences, Documento de trabajo, $\mathrm{N}^{\circ}$ 6, Santiago de Chile, Banco Central de Chile.

Calvo, G., L. Leiderman y C. Reinhart (1996): Inflows of capital to developing countries in the 1990s, The Journal of Economic Perspectives, vol. 10, № 2, Nashville, Tennessee, American Economic Association.

Cárdenas, M. y R. Steiner (2000): Private capital flows in Colombia, en F. Larraín (comp.), Capital Flows, Capital Controls and Currency Crises: Latin America in the 1990s, Michigan, Michigan University Press, Ann Arbor.

Cárdenas, M. y F. Barrera (1997): On the effectiveness of capital controls: the experience of Colombia during the 1990s,
Journal of Development Economics, vol. 54, № 1, Amsterdam, Elsevier Science Publishers, octubre.

De Gregorio, J., S. Edwards y R. Valdés (2000): Controls on capital inflows: do they work?, Journal of Development Economics, vol. 63, No 1, Amsterdam, Elsevier Science Publishers, octubre.

Edwards, S. (1998): Capital Flows, Real Exchange Rates and Capital Controls: Some Latin American Experiences, NBER Working Paper Series, No 6800, Cambridge, Massachusetts, National Bureau of Economic Research.

(1999): How effective are capital controls? The Journal of Economic Perspectives, vol. 13, № 4, Nashville, Tennessee, American Economic Association.

Eichengreen, B. (1999): Toward a New International Financial Architecture: A Practical Post-Asian Agenda, Washington, D.C., Instituto de Economía Internacional.

Enders, W. (1995): Applied Econometric Time Series, Nueva York, John Wiley and Sons.

Frankel, J. (1992): Measuring international capital mobility: a review, The American Economic Review, vol. 82, No 2, Nashville, Tennessee, American Economic Association, mayo.

Furman, J. y J. Stiglitz (1998): Economic crises: evidence and insights from East Asia, Brookings Papers on Economic Activity, $\mathrm{N}^{\circ} 2$, Washington, D.C., The Brookings Institution. 
Gourinchas, P., R. Valdés y O. Landerretche (2001): Lending Booms: Latin America and the World, NBER Working Paper Series, $\mathrm{N}^{\circ}$ 8249, Cambridge, Massachusetts, National Bureau of Economic Research, abril.

Hansen, H. y K. Juselius (1995): Cats in Rats: Cointegration Analysis of Time Series, Evanston, Illinois, Estima.

Harris, R. (1995): Using Cointegration Analysis in Econometric Modeling, Londres, Prentice Hall/Harvester Wheatsheaf.

Montiel, P. y C. Reinhart (1999): Do capital controls and macroeconomic policies influence the volume and composition of capital flows? Evidence from the 1990s, Journal of International Money and Finance, vol. 18, $\mathrm{N}^{\mathrm{o}}$ 4, Amsterdam, Elsevier Science Publishers.

Ocampo, J.A. (2003a): Capital account and counter-cyclical prudential regulations in developing countries, en R. FfrenchDavis y S. Griffith-Jones (comps.), From Capital Surges to Drought: Seeking Stability for Emerging Markets, Londres, Palgrave/Macmillan, por aparecer.

(2003b): Developing countries' anti-cyclical policies in a globalized world, en A. Dutt y J. Ros (comps.), Development Economics and Structuralist Macroeconomics: Essays in Honour of Lance Taylor, Aldershot, Edward Elgar.

Ocampo, J.A. y C. Tovar (1997): Flujos de capital, ahorro e inversión en Colombia, 1990-1996, en R. Ffrench-Davis y H. Reisen (comps.), Flujos de capital e inversión productiva: lecciones para América Latina, Santiago de Chile, McGraw-Hill.
Reinhart, C. y S. Dunaway (1996): Dealing with capital inflows: Are there any lessons?, Research for Action, No 28, Helsinki, Universidad de las Naciones Unidas/Instituto Mundial de Investigaciones de Economía del Desarrollo, septiembre.

Rincón, H. (1999): Efectividad del control a los flujos de capital: un reexamen empírico de la experiencia reciente en Colombia, Borradores semanales de economía, Bogotá, D.C., Banco de la República.

Rodrik, D. y A. Velasco (2000): Short-term capital flows, en B. Pleskovic y J.E. Stiglitz (comps.), Annual World Bank Conference on Development Economics, 1999, Washington, D.C., Banco Mundial.

Schulze, G. (2000): The Political Economy of Capital Controls, Cambridge, Massachusetts, Cambridge University Press.

Valdés, S. y M. Soto (1998): The effectiveness of capital controls: theory and evidence from Chile, Empirica, vol. 25, $\mathrm{N}^{\circ} 2$, Amsterdam, Kluwer Academic Publishers.

Villar, L. y H. Rincón (2003): The Colombian economy in the nineties: capital flows and foreign exchange regimes, en A. Berry (comp.), Critical Issues in Financial Reform: A View from the South, New Brunswick, New Jersey, Transaction Publishers, por aparecer.

Williamson, J. y M. Mahar (1998): A survey of financial liberalization, Princeton Essays in International Finance, $\mathrm{N}^{\circ} 211$, Princeton, Departamento de Economía, Universidad de Princeton, noviembre. 